\title{
Multiparameter Control Strategy and Method for Cutting Arm of Roadheader
}

\author{
Pengjiang Wang $\mathbb{D},{ }^{1}$ Yang Shen $\mathbb{D}^{1},{ }^{1}$ Xiaodong Ji $\mathbb{D},{ }^{1,2}$ Kai Zong $\mathbb{D}^{3}$, Weixiong Zheng $\mathbb{D},^{1}$ \\ Dongjie Wang $\mathbb{D}^{1}$, and Miao $W u \mathbb{D}^{1}$
}

\author{
${ }^{1}$ School of Mechanical Electronic and Information Engineering, China University of Mining and Technology (Beijing), \\ Beijing 100083, China \\ ${ }^{2}$ Shijiazhuang Coal Mine Machinery Co., Ltd., Shijiazhuang 050000, China \\ ${ }^{3}$ School of Mechanical Engineering, Tsinghua University, Beijing 100083, China
}

Correspondence should be addressed to Yang Shen; yangshenbir1993@126.com

Received 21 March 2021; Revised 5 July 2021; Accepted 8 July 2021; Published 17 July 2021

Academic Editor: Vasudevan Rajamohan

Copyright (c) 2021 Pengjiang Wang et al. This is an open access article distributed under the Creative Commons Attribution License, which permits unrestricted use, distribution, and reproduction in any medium, provided the original work is properly cited.

\begin{abstract}
A multiparameter control strategy and method for the cutting arm of a roadheader is proposed through the operation analysis of roadheader. The method can address the problems of low intelligence and low cutting efficiency faced by the roadheader in the cutting process. The control strategy is divided into two parts: the cutting load identification part and the swing speed control part. The former part is designed using a backpropagation neural network that is optimized by an improved particle swarm optimization algorithm. The latter part is optimally designed using a fuzzy PID controller with improved simulated annealing particle swarm optimization. The simulation analysis in SIMULINK showed that the response time was reduced, proving the robustness of the method. In addition, experimental studies verified the good control effect of the method under different cutting states. The proposed method uses multiparameter to intelligently change the swing speed, providing a theoretical and practical basis for the realization of intelligent and unmanned cutting of roadheader.
\end{abstract}

\section{Introduction}

With the development of coal mining technology and the increasingly strict safety requirements, the intelligentization of coal mining equipment has become an inevitable trend. The intelligent control of roadheader, which is one of the most important equipment for underground excavation work in coal mines, especially for the roadway drivage, has always been a research topic of interest in the field of coal science [1-3]. Implementing intelligent control of roadheaders is challenging due to the difficulties in obtaining information on coal and rock properties and working conditions during operation. As a result, in most cases, manual control is used, which is time-consuming and unreliable, and it puts workers in a high-risk environment. Therefore, realizing intelligent control is an urgent issue in underground coal mines [4-6].
The cutting arm, which is the key cutting component of the roadheader, is driven by a hydraulic cylinder. The working process of a roadheader is to cut coal and rock using the swing of the cutter arm and the rotation of the cutter head [7-9]. During tunneling, the constantly changing cutting load can cause the cutting motor load power to be extremely unstable, leaving the roadheader in an under- or overloaded state, which undermines the cutting efficiency [10-13]. At the same time, sudden changes in coal and rock loads can easily cause damage to cut-off mechanism components, resulting in large economic losses. In addition, the indeterminate load generates a large amount of dust during cutting, posing a serious safety hazard for miners [14-17]. Therefore, it is necessary to control the swinging speed of roadheader in real time to ensure that the swinging speed can adapt to the change of coal and rock hardness, so as to address drastic load 
changes and improve working efficiency when cutting the randomly distributed coal and rocks.

Some scholars have conducted research on cutting control for roadheader. Yang and Wang [18] proposed an intelligent cutting control method for cutting section of roadheader. The cutting motor current was regarded as the criterion of the change of cutting load, and the telescopic speed of hydraulic cylinders was adjusted based on the PID control. Li and Liu [19] proposed a fuzzy control method based on GAs optimization, in which the cutting motor current is used as a feedback signal to change the cutting arm swing speed. He and Jiao [20] proposed a fuzzy PID control system for roadheader and used the current of cutting motor as the basis to judge the theoretical linear velocity of the cutting arm to control the hydraulic cylinder. Gao et al. [21] proposed a PID control method for the cutting arm swing speed. In this method, the cutting motor current is regarded as a criterion for cutting load variation, and the difference between the current and its rated value is regarded as the input to control the rate of change of lifting and angling cylinder stroke. Huang et al. [22] proposed an adaptive cutting technology of roadheader. Based on the PID control method, the set value of constant power of cutting motor is designed as the initial signal, and the swing speed of cutting arm is automatically adjusted to keep the cutting power at its set value. A lot of work has been done in the above literatures to achieve the control of the swing speed of the cutting arm, but these methods suffer from the problems of incomplete and unstable load recognition, because a single sensor signal is considered. Therefore, the designed control methods cannot fully and accurately estimate the variation of the cutting load, and the control efficiency and stability cannot be optimized.

It is essential to control the swing speed of the cutting arm through multiparameter information measured underground. Related research has made a preliminary exploration of identifying the cutting load of roadheader by multiparameter information and laid the methodological basis. Through a nonlinear dynamics analysis of the cutting mechanism of a roadheader, Huang [23] concluded that the cutting arm's strength vibration directly impacts the cutting performance. In the studies of Ebrahimabadi et al. [24] and Jasiulek and Stankiewicz [25], the roadheader with an artificial neural network was employed to identify the hardness of coal or rocks for cutting to improve cutting performance. According to Jasiulek and Świder [26], an artificial neural network based on various parameters was used to identify the cutting load to obtain a suitable angular speed for the cutting arm swing. According to Zhao and Wang [27], to improve cutting efficiency, they combined the principal component analysis and radial basis function neural networks to predict the cutting performance. Their research demonstrated that estimating cutting loads using multiparameter information can significantly increase the confidence level. According to Yang et al. [28], cutting loads were determined using various working condition parameters for coal mining machines. The collected parameter signals include current signals, vibration acceleration signals, and barrel pressure signals as references for the identification of coal mining machine load. Wang et al. [29] used multineural networks and evidence theory, combined with multiparameter information, to identify the cutting dynamic loads of a cutting machine. It turned out that the multiparameter information significantly improved the confidence level of identification and meets the need for load identification in underground coal mines.

On the other head, the robustness of the control process needs to be very much considered. In response to the nonlinear and complex dynamic behavior of the cutting process in roadheader, the main control methods for the cutter arm swing speed include self-adaptive control [30], robust control [31], sliding-mode control [32], and neural network control [33]. For instance, Modiri and Mobayen [30] proposed an adaptive sliding mode control method based on the synchronization of fractional order uncertain chaotic systems. Esmaeilzadeh et al. [31] proposed a sliding mode control method for controlling the attitude of spacecraft with high accuracy. Pujol-Vazquez et al. [32] proposed a robust control method based on $H \infty$ theory and applied it to the control of a hexapod robot. In addition, Rahmani et al. [33] proposed a robust control method based on RBFN with applications in inverted pendulums. In terms of the special situation of multiparameter control in underground coal mines, the design of neural network controllers can effectively ensure the robustness of control.

In order to get better performance from any controller, its parameters need good optimization. Various optimization algorithms are widely used in industrial control systems, such as genetic algorithms, ant colony algorithms, bacteria foraging optimization algorithms, intelligent crow search algorithms, and particle swarm algorithms [34-37]. Du et al. [36] used PSO optimization algorithms for power-sharing hybrid electric vehicle energy management strategies. Kashyap and Parhi [37] used a particle swarm algorithm to rectify a conventional PID controller to achieve the humanoid robot gait stability. Elsisi et al. [38] proposed a new optimization algorithm, named the mayfly optimization algorithm (MOA), to find the optimal parameters of the proportional integral derivative (PID) controller for Wind Energy Conversion Systems Against Wind Speed Fluctuations. Moreover, the combination of simulated annealing algorithms with others has certain advantages. For example, Zhang et al. [39] optimized wireless sensor networks by combining simulated annealing with the Gray Wolf algorithm. Luo et al. [40] proposed a method based on simulated annealing and genetic algorithms for solving the problem of distributing cocoon loads among workers in cocoon production systems. Consequently, an improved particle swarm optimization algorithm is proposed to prevent the BP neural network from falling to a minimum. An improved annealing particle swarm algorithm is used to optimize the fuzzy PID parameters to improve the robustness of the system.

In this paper, we propose a multiparameter control strategy and method for cutting arm of the roadheader. This paper aims to improve the intelligence of the roadheader, extend the life of roadheading machines, and improve the efficiency of tunneling. The main contributions of the paper are as follows: 
(1) A new multiparameter identification method for cutting loads is proposed. Meanwhile, an improved particle swarm algorithm is used to optimize BP neural networks. Such designs of the controller help overcome the shortcomings of unreliable and incomplete single parameters.

(2) Based on multiple parameters, we propose a novel method of swing speed control over the cutting arm. An improved simulated annealing particle swarm algorithm is employed to optimize the fuzzy PID controller to reduce response time and improve stability.

(3) Finally, an experiment has been designed to verify the advantages of the control method in speed, stability, and robustness.

\section{Working Principle of the Cutting Arm and Control Strategy}

2.1. Working Principle of the Cutting Arm. Boom-type roadheader belongs to the partial-size tunneling machine. The cutting arm is fixedly connected to the revolving platform. The horizontal swing process of cutting arm is driven by a pair of symmetrically arranged angling cylinders. When the roadheader cuts horizontally, one cylinder of the hydraulic cylinder extends, and the other cylinder shortens simultaneously, driving the rotating platform in a concerted movement and causing the cutting arm to swing around its center of rotation, as shown in Figure 1. The vertical swing of the cutting arm is driven by a pair of parallel and symmetrical lifting cylinders. When the roadheader is cutting vertically, the lifting cylinder extends or shortens simultaneously, driving the cutting arm to swing up or down, as shown in Figure 2.

The forming process of roadway cross section requires repeated horizontal and vertical cutting of the cutting arm. At work, the angling and lifting cylinders drive the cutting arm to swing horizontally and vertically. Meanwhile, the cutting head rotates, so that the coal and rock are broken and fallen. As for the cutting process, the cutting arm swings horizontally to one expected border on one side and swings upward vertically for a certain height and then swings horizontally in the reverse direction to another expected border, before it swings upward vertically. The cutting arm keeps moving until the cutting operation of the whole cross section is finished. The moving path of the cutting arm is shown in Figure 3, where the coordinate system XOY is an imaginary coordinate system in the cross section of the roadway.

\subsection{Analysis of Cutting Parameters}

2.2.1. Cutting Current I. The cutting motor current varies with the hardness of coal and rocks during the tunneling process. The roadheader is driven by a three-phase asynchronous motor, and the active power $N$ can be expressed as

$$
N=\sqrt{3} U I \cos \varphi \text {. }
$$

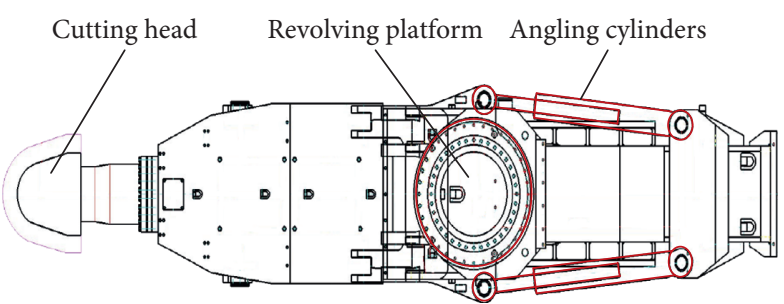

Figure 1: Structure of horizontal cutting for roadheader.

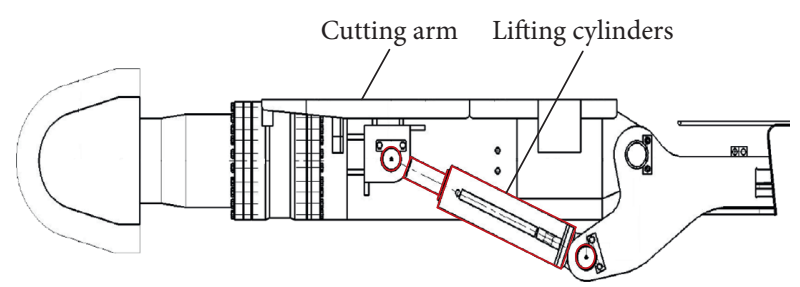

FIgURE 2: Structure of vertical cutting for roadheader.

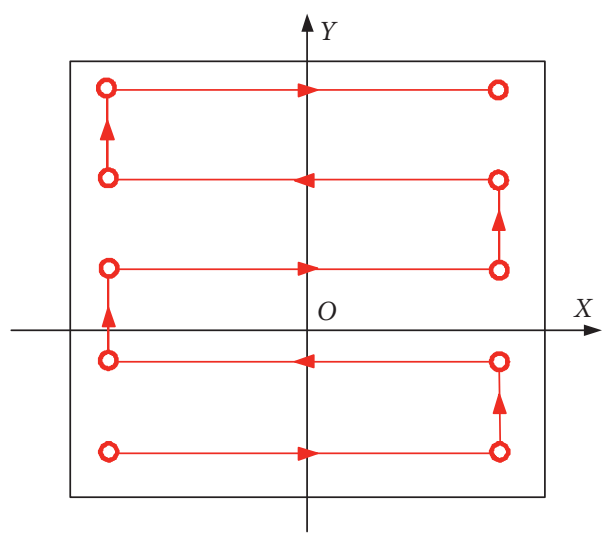

FIgURE 3: Moving path of the cutting arm.

Here, $U$ is the cutting voltage, $I$ is the current, and $\cos \varphi$ is the power factor of the cutting motor.

The active power consists of two parts: the cutting power $P$ and the power losses. The power loss consists of the mechanical loss $P_{\mathrm{m}}$, the core loss $P_{\mathrm{Fe}}$, the copper loss caused by the stator winding $P_{\mathrm{Cu} 1}$ and the rotor winding $P_{\mathrm{Cu} 2}$. Among them, $P_{\mathrm{m}}$ and $P_{\mathrm{Fe}}$ are constant. $P_{\mathrm{Cu} 1}, P_{\mathrm{Cu} 2}$ and $P$ can be, respectively, expressed as follows:

$$
\begin{aligned}
P_{\mathrm{Cu} 1} & =K_{1} I^{2}, \\
P_{\mathrm{Cu} 2} & =\frac{s}{1-s}\left(P+P_{m}\right), \\
P & =P_{k}(f)\left(K_{2}+K_{3} v\right),
\end{aligned}
$$

where $s$ is the slip rate, $P_{k}(f)$ is the index of coal-rock hardness, and $K_{1}, K_{2}$, and $K_{3}$ are constants and the correlation coefficients of the loads on the cutting head. Besides, $v$ refers to the cutting arm swing speed.

Their relation is as follows: 


$$
N=P_{\mathrm{Fe}}+P_{\mathrm{Cu} 1}+P_{\mathrm{Cu} 2}+P_{\mathrm{m}}+P .
$$

Substituting formulas(1)-(4) into formula (5) yields

$$
\sqrt{3} I U \cos \varphi=P_{\mathrm{Fe}}+K_{1} I^{2}+\frac{P_{\mathrm{m}}}{1-s}+\frac{P_{k}(f)\left(K_{2}+K_{3} v\right)}{1-s} \text {. }
$$

From equation (6), it can be seen that $f, v$, and $I$ are variable values, while the rest are constant values. When the hardness $f$ increases, the cutting current $I$ increases due to the increased load on the cutting motor. As a result, the cutting arm swing speed $v$ decreases. In other words, when a roadheader cuts hard rock, the cutting load caused by the cutting head and the cutting current $I$ become larger. Thus, the swing speed $v$ of the cutting arm should decrease. When a roadheader cuts softer coal or rock, the cutting load on the cutting head and the cutting current $I$ will be smaller, so the cutting arm swing speed $v$ should increase.

2.2.2. Cylinder Pressure P. During the cutting process, hydraulic cylinders on the roadheader provide the power for the swing of the cutting arm. Therefore, the pressure of the hydraulic cylinder can estimate the load on the cutting head, which is essential to determine the cutting state of the overall control system.

2.2.3. Vibration Acceleration Acc. The roadheader usually generates violent vibrations due to changes in load during the cut-off process. Studies of the roadheader have shown that the greater the cutting loads encountered during the roadheading process, the stronger the vibration signal. The vibration of the cutter arm is strongest, and the resulting acceleration signal is a good reflection of the changes in load $[41,42]$. Hence, the vibration acceleration Acc can provide an essential criterion for determining the control state.

2.3. Control Strategy. During the cutting process, continuously changing cutting load causes the output power of the cutting motor to be unstable. The output power is greatly influenced by the feed speed of the cutting mechanism, namely, the cutting arm swing speed. Therefore, the constant power control becomes the goal of dynamic adjustment of the swing speed. When the hardness of coal or rock is larger, the output power exceeds its rated power. Thus, the swing speed of the cutting arm should be reduced to decrease the load on cutting motor and maintain the output power at its rated power to protect the motor. When the coal and rock hardness is low, the output power is less than its rated power, so the swing speed of the cutting arm should be increased to keep the output power at the rated range to improve the roadheader efficiency.

The cutting motor current will increase with coal and rock hardness due to the larger load on the cutting head [43]. The cylinder pressure will also increase along with the load [44]. The vibration acceleration also increases due to the sudden impact of the load [45]. Similarly, when the hardness of coal and rock drops, the three parameters will also decrease. Therefore, the current $I$ of cutting motor, pressure $P$, and vibration acceleration Acc of cutting arm have been selected as the criteria to represent the change of hardness of coal and rock collectively. The swing speed $v$ of cutting arm is regarded as the control object. Figure 4 shows the control strategy for the cutting arm swing speed.

Control strategy is divided into two parts: the cutting load identification and swing speed control parts. The cutting load identification uses current $I$, pressure $P$, and vibration acceleration Acc as the input of particle swarmoptimized backpropagation neural network algorithm (IPSO-BP) controller. In addition, measurement data recorded by an on-board high-capacity data logger is used to train this controller. During the operation of the roadheader, the three control parameters are detected simultaneously and transmitted to IPSO-BP controller. Afterwards, the signal characterizing the magnitude of the cutting load is output by the controller. In the swing speed control part, the output signal by the BP neural network controller is introduced into the fuzzy PID controller to improve the stability and efficiency of the speed control over the cutting arm swing. Furthermore, the Fuzzy PID controller is optimized by improved simulated annealing particle swarm optimization (ISAPSO). The swing speed control of the cutting arm is achieved by controlling the opening size of the electrohydraulic proportional valve to control the telescopic amount of the lifting and rotating cylinder.

\section{Design of the BP-NN Controller}

During the operation of a roadheader, the variation of the cutting load is influenced by multiple parameters. However, an accurate mathematical model of the load between these parameters and the cutting head cannot be established. BP neural networks can implement complex nonlinear mapping, helping solve problems with complex relationships between multiple parameters.

3.1. Structure of BP Neural Network. Based on the control strategy proposed in Section 2, the neural network controller structure applied to cutting load identification uses the key cutting parameters as input vectors, mainly $I, P$ and Acc, and adjusts th $e$ network weights to minimize the total mean square error of the network output. The structure consists of three layers [46, 47], among which the output layer is the value representing the cutting load. Figure 5 shows the structure diagram.

\subsection{Acquisition of Multiparameter Information Samples.}

The sample is from the underground experiment data, and the roadheader is EBZ160 boom-type roadheader in the experiment carried out in XingDong mine. The cutting motor of EBZ160 type roadheader is the ybud-200/110-4/ $8(1140)$ explosion-proof double-speed motor. Equipped with abundant monitoring sensors, the motor can detect current $I$ in real time. The BYD-60 pressure transmitter is used to measure the cutting arm cylinder pressure. The selfdeveloped GBC1000 accelerometer measures the vibration 


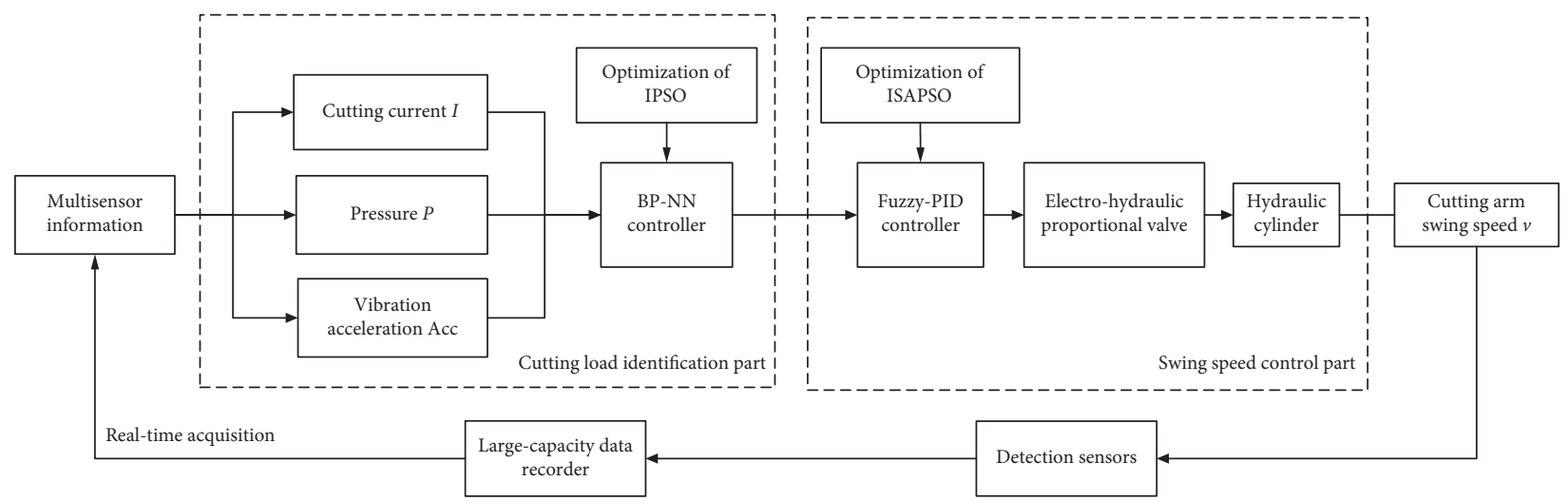

FIgURE 4: Control strategy for the cutting arm swing speed.

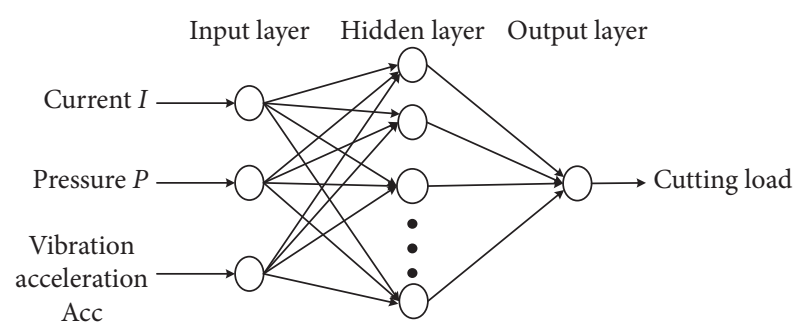

Figure 5: Structure diagram of the BP controller.

acceleration signal. All data are stored in the airborne large capacity data recorder. Pictures of the experiment equipment are shown in Figure 6.

We have processed the underground experiment data [43-45], and 2500 groups of the data were selected as sample for controller. Parts of samples data are shown in Tables 1 and 2 .

\subsection{Improved Particle Swarm Optimization Algorithm.} Particle swarm optimization (PSO) is an algorithm proposed by Kennedy and Eberhart in 1995 in search of the best solution. However, in terms of the standard PSO algorithm, a linear decrease in the key parameter $w$ would reduce the convergence performance of the algorithm, causing the particles to fall into local minima.

Therefore, this study uses a nonlinear decreasing weight PSO (IPSO) to improve the shortcomings of the standard PSO. The equation of IPSO algorithm is $[48,49]$

$$
w=w_{\max }-\left(w_{\max }-w_{\max }\right) \times \tan \left[\left(\frac{\pi}{4}\right) \times\left(\frac{t}{t_{\max }}\right)\right],
$$

where $w_{\max }$ and $w_{\min }$ are the maximum and minimum values of the inertia weight $w$, respectively, typically taken as $w_{\max }=0.9, w_{\min }=0.4 . t$ denotes the current iteration step, while $t_{\max }$ refers to the maximum iteration step.

The IPSO-BP is an optimized algorithm combining the IPSO with the BP. The role of IPSO is to optimize the initial connection weights and thresholds of the BP neural network. The optimized IPSO-BP controller can compensate for the tendency of $\mathrm{BP}$ neural networks to converge into local minimum values with strong optimization performance. The optimization process is shown in Figure 7.

3.4. Neural Network Controller Performance Testing and Validation. After training 2000 sets of samples, we set the neurons in the hidden layer to 9 . The activation function is tansig, and the output activation function is purelin. The goal of mean square error is set to $1 \times 10^{-4}$.

The number of particle swarm bits is calculated as 56 in the IPSO, while the learning factor is set to 2 . Table 3 shows the training time and the number of iterations of the unoptimized BP neural network controller and the optimized IPSO-BP controller.

A shorter training time for the IPSO-BP controller can be obtained from Table 3. In addition, the number of iterations is also less than BP. We test the BP controller and IPSO-BP controller separately using additional 500 sets of samples. The results of the test are shown in Figure 8. As can be seen from the test results, the IPSO-BP controller has higher output accuracy and faster convergence.

In addition, 100 sets of multiparameter information under different working conditions have been selected, and the relative errors between the actual loads under different working conditions and the loads output by the IPSO-BP neural network controller have been counted, which can be seen in Figure 9. The results show that the relative error of the load is within $2.5 \%$, which fully satisfies the requirements for the accuracy of identifying the cutting load.

\section{Design of the Fuzzy PID Controller (F-PID)}

The design principle of fuzzy PID control is to make the roadheader work efficiently and stably. Based on the cutting load information obtained from the BP-NN controller, the cutting arm swing speed can be intelligently and adaptively adjusted according to the different cutting load during the cutting process.

4.1. Fuzzy Rules and Membership Functions. PID controllers have been used in a wide range of industrial control processes for more than half a century [50-53]. However, when 


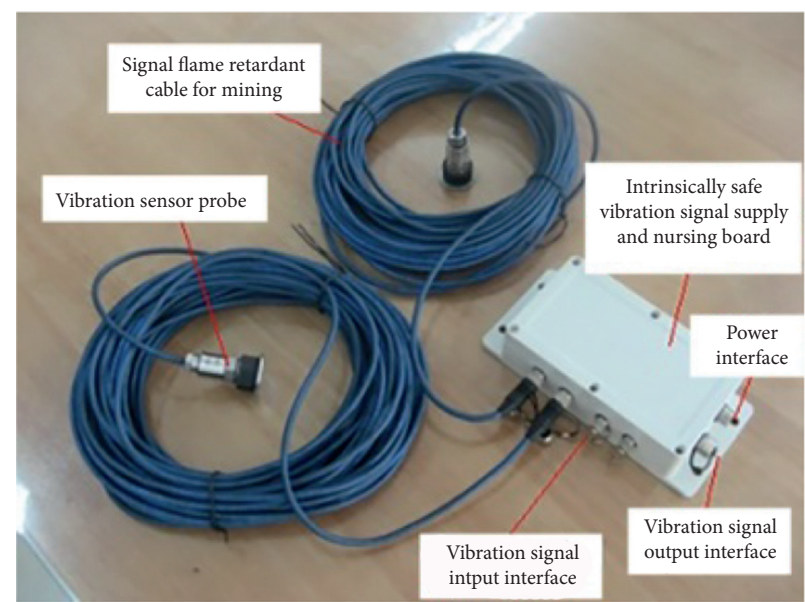

(a)

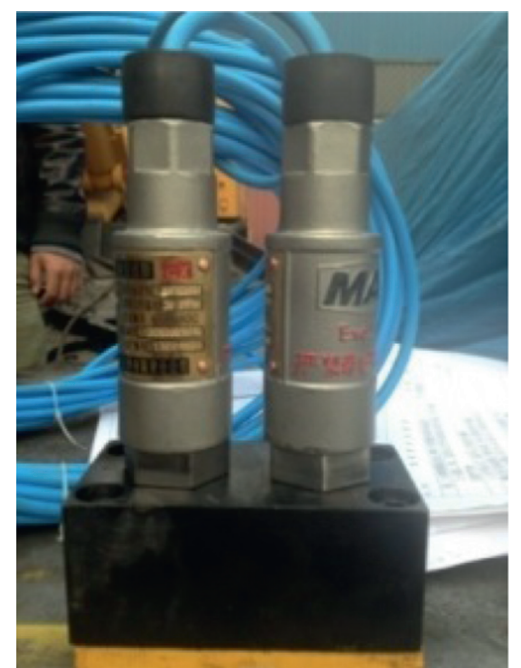

(b)

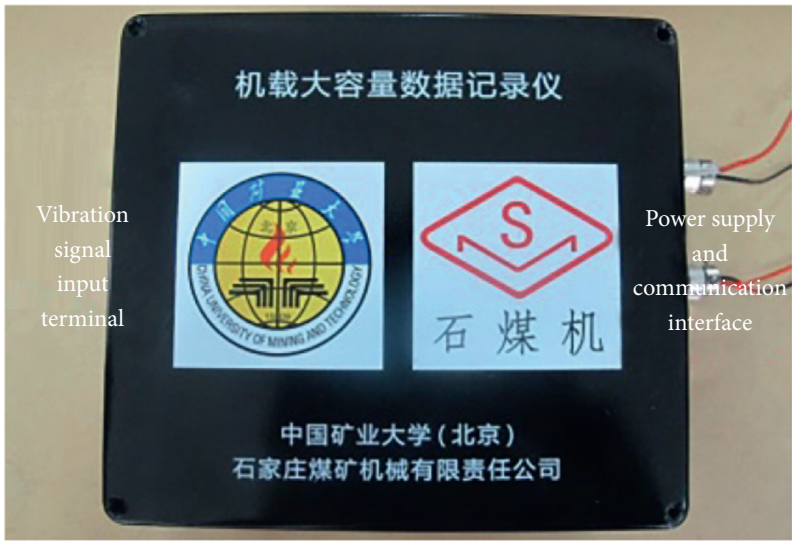

(c)

FIGURE 6: Sensors required for experiments. (a) GBC1000 vibration acceleration sensor. (b) BYD-60 pressure transmitter. (c) Large capacity data recorder.

TABLE 1: Some of the sample data under horizontal swing cutting conditions.

\begin{tabular}{lccc}
\hline Operating parameter & Current $I(\mathrm{~A})$ & Pressure $P(\mathrm{MPa})$ & Vibration acceleration Acc $(\mathrm{g})$ \\
\hline 1 & 72.01 & 12.46 & 3.44 \\
2 & 185.13 & 19.66 & 6.31 \\
3 & 175.22 & 8.37 & 10.23 \\
4 & 180.16 & 20.98 & 7.86 \\
5 & 44.28 & 23.82 & 5.62 \\
6 & 108.06 & 19.88 & 5.96 \\
7 & 26.03 & 6.13 & 0.81 \\
8 & 53.24 & 6.68 & 0.92 \\
9 & 73.84 & 13.85 & 2.89 \\
10 & 105.06 & 19.73 & 5.85 \\
\hline
\end{tabular}

traditional PID control is used to study nonlinear timevarying systems, the algorithm is less robust to perturbations in the system parameters. The combination of fuzzy algorithm and PID can linearly adjust the output of PID control, which produces better control effect.

The formulation of fuzzy rules is based on the output obtained from the IPSO-BP controller, combined with the changing law of multiparameter information. The F-PID controller has two input items and three output items. The input terms are the data $e$ and the change rate ec of the data output from IPSO-BP controller. The $k p, k i$, and $k d$ are the fuzzy output terms. Both input and output items use seven fuzzy membership functions, and 49 fuzzy rules are set, as shown in Table 4.

The selection of fuzzy membership function should be close to the actual cutting condition as much as possible, 
TABLE 2: Some of the sample data under vertical swing cutting condition.

\begin{tabular}{lccc}
\hline Operating parameter & Current $I(\mathrm{~A})$ & Pressure $P(\mathrm{MPa})$ & Vibration acceleration Acc $(\mathrm{g})$ \\
\hline 1 & 80.25 & 15.55 & 3.37 \\
2 & 92.25 & 18.13 & 4.57 \\
3 & 126.35 & 21.52 & 6.04 \\
4 & 64.33 & 10.08 & 2.35 \\
5 & 55.54 & 9.23 & 1.75 \\
6 & 139.2 & 21.84 & 7.62 \\
7 & 98.25 & 19.42 & 5.17 \\
8 & 126.35 & 21.52 & 6.04 \\
9 & 64.59 & 11.05 & 2.48 \\
10 & 100.25 & 19.85 & 5.37 \\
\hline
\end{tabular}

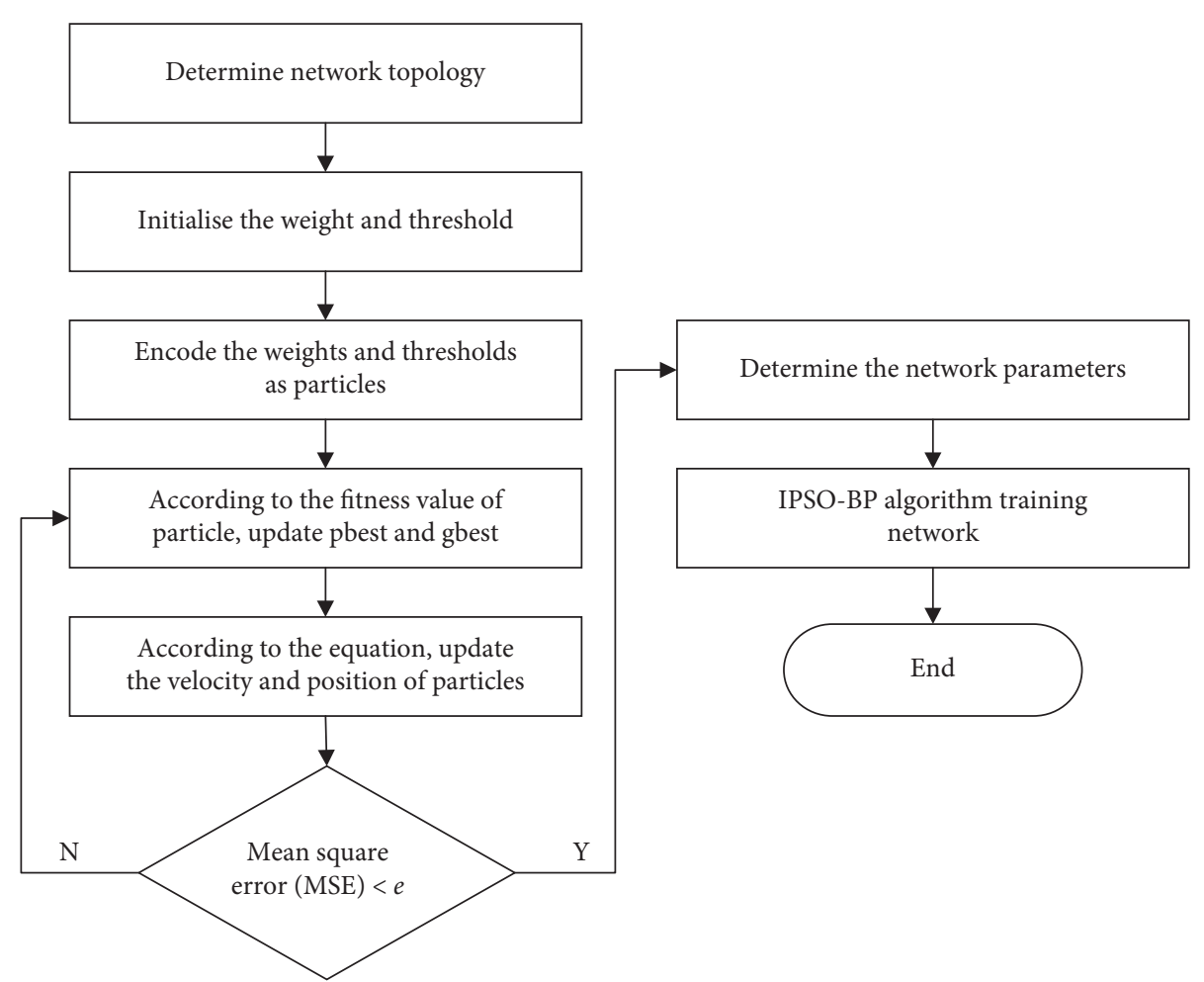

FIGURE 7: IPSO-BP neural network optimization flowchart.

TABLE 3: Comparison of performance between BP controller and IPSO-BP controller.

\begin{tabular}{lcccccccc}
\hline \multirow{2}{*}{ Category } & \multicolumn{4}{c}{ Training time $(\mathrm{s})$} & & \multicolumn{3}{c}{ Iteration times } \\
& 1 & 2 & 3 & Average value & 1 & 2 & 3 & Average value \\
\hline BP & 1.9321 & 1.6473 & 1.6318 & 1.7371 & 56 & 45 & 40 & 47 \\
IPSO-BP & 1.0136 & 1.0627 & 0.8199 & 0.9654 & 36 & 41 & 38 & 38 \\
\hline
\end{tabular}

consistent with the load characterized by the multiparameter information. After repeated debugging, we choose 5 triangular membership functions, an $S$ membership function, and a $Z$ membership function. The membership functions of the F-PID controller are shown in Figure 10.

As shown in Figure 10, the inputs $e$ and $e c$ have values ranging from -3 to 3 , and fuzzy controller determines the values of the outputs. Furthermore, the area center of gravity method is used to solve the fuzzy problem. The fuzzy controller inputs and outputs surface map are shown in Figure 11.
4.2. Optimization of the F-PID Controller. As for the control of mechanical engineering classes, it is difficult for technicians to derive and extract suitable fuzzy control rules due to the incompleteness and subjectivity of fuzzy rules. Therefore, the extraction and optimization of fuzzy control rules are significant for the F-PID control process. The PSO algorithm has good optimization characteristics. Thus, combined with the simulated annealing algorithm, an improved simulated annealing particle swarm optimization algorithm (ISAPSO) is formed.

The Metropolis criterion is introduced into the PSO algorithm by setting the value of the objective function [54]. 


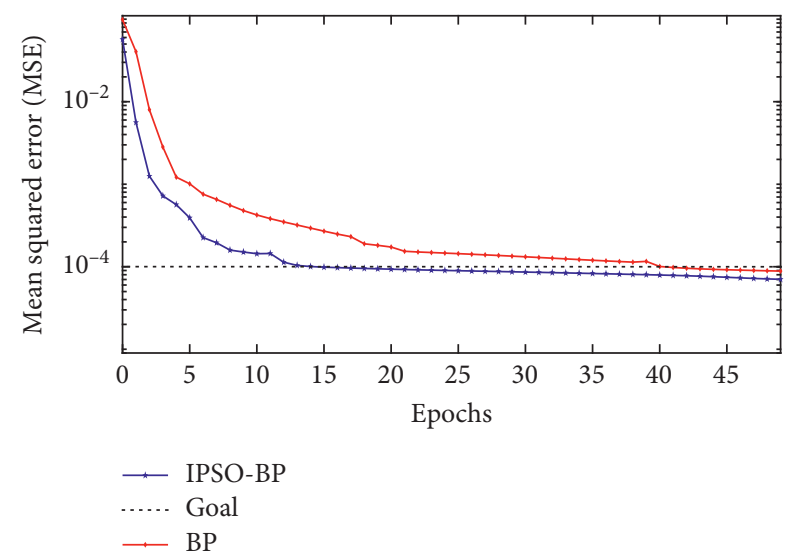

Figure 8: Neural network controller test results.

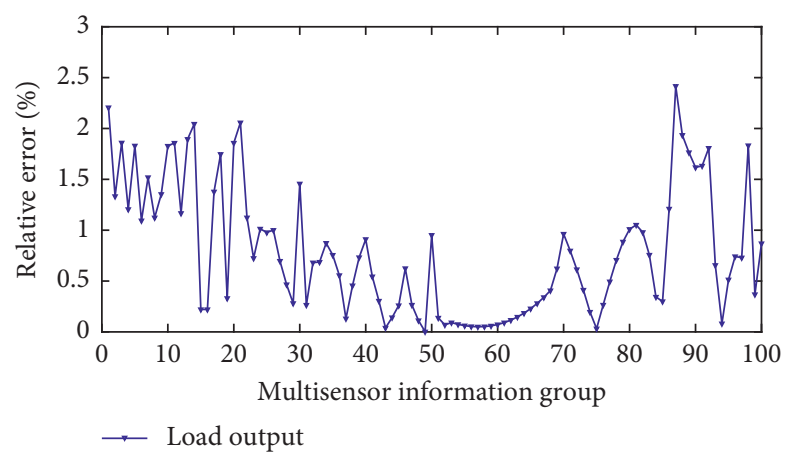

Figure 9: Relative error in load output.

TABLE 4: Rule base for F-PID.

\begin{tabular}{lccccccc}
\hline$e$ & & & \multicolumn{9}{c}{$e c$} \\
& NB & NM & NS & Z & PS & PM & PB \\
\hline NB & NB & NB & NB & NB & NM & NS & Z \\
NM & NB & NB & NB & NM & NS & Z & PS \\
NS & NB & NB & NM & NS & Z & PS & PM \\
Z & NM & NM & NS & Z & PS & PS & PM \\
PS & NM & NS & Z & PS & PM & PM & PB \\
PM & NS & Z & PS & PM & PB & PB & PB \\
PB & Z & PS & PM & PM & PB & PB & PB \\
\hline
\end{tabular}

If there is a value better than the objective function, then the new solution will be accepted. Otherwise, the probability $P_{T}$ is computed, and the magnitude of $P_{T}$ is compared with $P$ (a random number between 0 and 1). If $P_{T}$ is large, the new solution will still be accepted. Otherwise, the original solution will be taken. The formula for calculating $P_{T}$ is shown in the following formula:

$$
P_{T}=\exp \left(\frac{f\left(x_{i}^{T}\right)-\left(x_{j}^{T}\right)}{T}\right),
$$

where $x_{i}^{T}$ and $x_{j}^{T}$ denote the solution when the control parameter is $T$, the temperature. $T$ decreases as the number of iterations increases, allowing the algorithm to accept deteriorating solutions with decreasing probability. Finally, a globally optimal solution is converged.
The combination of the two algorithms can avoid the particle's inability to search the global optimal point due to the algorithm's prematurity and ensure the local fast searching ability of the algorithm. Thus, the balance between the global searching ability and the local searching ability can be flexibly adjusted.

Figures 12 and 13 show the schematic diagram and flow chart of the ISAPSO algorithm for F-PID controller parameter optimization. The optimization parameters are fuzzy rule weights, $\mathrm{Ke}$, and $\mathrm{Kec}$, representing the error and error rate quantization factors, respectively. The value range of fuzzy rule weight is 0 to 1 , while the value range of quantization scaling factor is 0 to 10. ITAE integral criterion is used for the fitness function.

\section{Simulation Analysis}

The mathematical model has been developed. This method is simulated in Simulink and compared with fuzzy PID control and conventional PID control.

5.1. Modeling of the Control System. The control system is composed of IPSO-BP neural network controller, proportional amplifier, ISAPSO optimized F-PID controller, electrohydraulic proportional valve, driving hydraulic cylinder of cutting arm, the conversion link between the swing angle of the cutting arm and the stroke of the hydraulic cylinder, and the conversion link between the swing speed and the swing angle speed of the cutting arm. The IPSO-BP controller can be directly exported as Simulink module in Section 3, while the mathematical model or transfer function needs to be established for other links.

The proportional amplifier can process, amplify, and and convert the controller's output signal and output a current signal to control the electrohydraulic proportional directional valve. Its mathematical model is

$$
K_{a}=\frac{I(s)}{E(s)} .
$$

In equation (9), $K_{a}$ is the gain of the proportional amplifier, $I(s)$ is the output signal of the proportional amplifier, and $E(s)$ is the input signal of the proportional amplifier.

The transfer function of the electrohydraulic proportional valve is

$$
\frac{Q_{L}(s)}{I(s)}=\frac{K_{q}}{\left(1 / \omega_{v}^{2}\right) s^{2}+\left(2 \delta_{v} / \omega_{v}\right) s+1} .
$$

In equation (10), $Q_{L}(s)$ is the flow of the hydraulic cylinder, $K_{q}$ is the flow gain of the valve, $\omega_{v}$ is the intrinsic frequency of the valve, and $\delta_{v}$ is the damping ratio of the valve.

The transfer function of the hydraulic cylinder can be expressed as

$$
\frac{L(s)}{Q_{L}(s)}=\frac{1 / A}{s\left(\left(1 / \omega_{h}^{2}\right) s^{2}+\left(2 \delta_{h} / \omega_{h}\right) s+1\right)} .
$$

In equation (11), $L(s)$ is the piston rod stroke of hydraulic cylinder, $A$ is the cross-sectional area of the head port of 


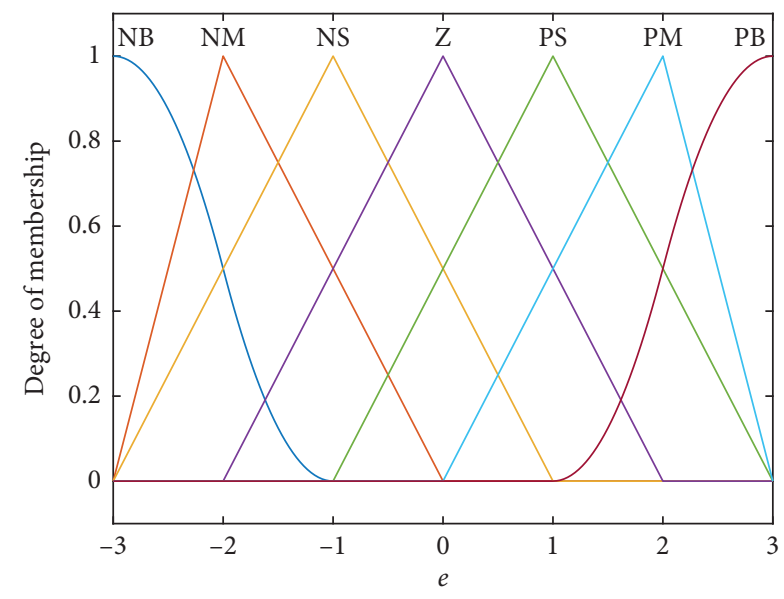

(a)

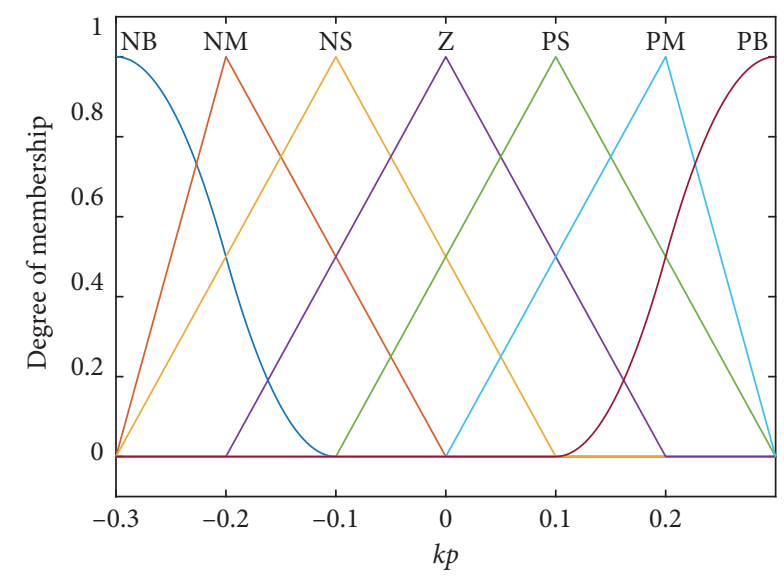

(c)

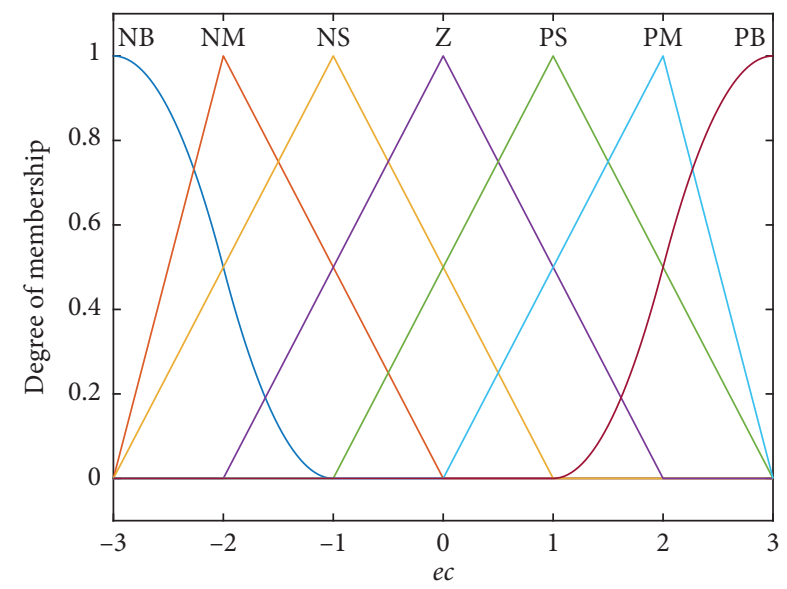

(b)

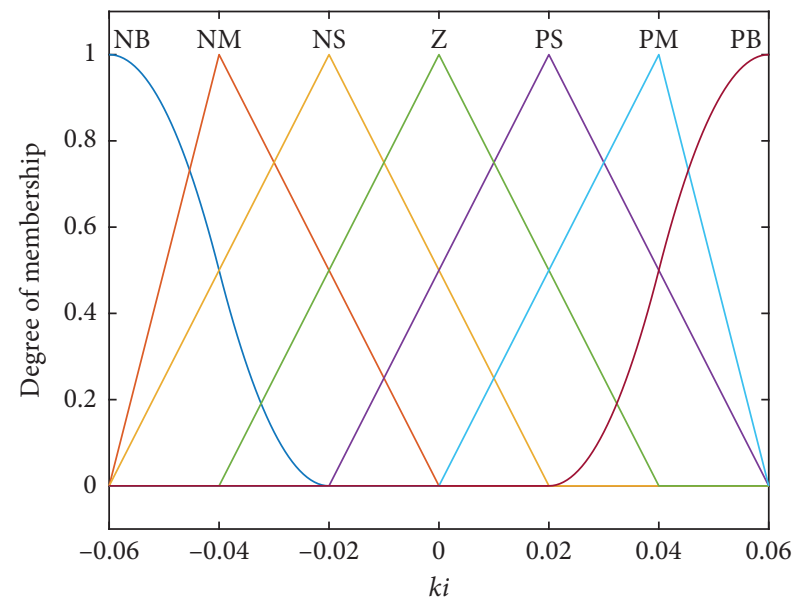

(d)

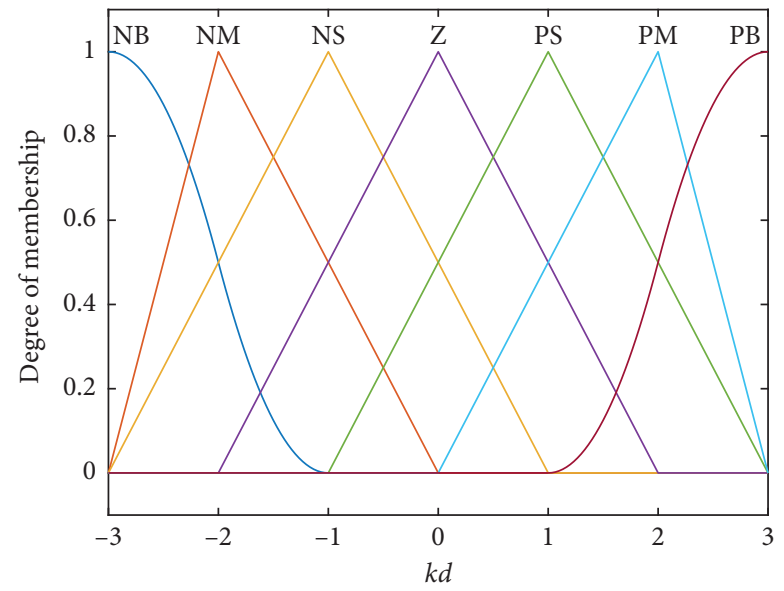

(e)

Figure 10: Membership functions of F-PID controller. (a) e. (b) $e c$. (c) $k p$. (d) $k i$. (e) $k d$.

cylinder, $\delta_{c}$ is the equivalent damping ratio of the hydraulic cylinder system, and $\omega_{h}$ is the intrinsic frequency of hydraulic cylinder.

The mathematical model of the conversion link between the cylinder stroke and the swing angle of cutting arm is

$$
K_{b}=\frac{B(s)}{L(s)} .
$$

In equation (12), $K_{b}$ refers to the conversion gain between the cylinder stroke and the swing angle of the cutting 


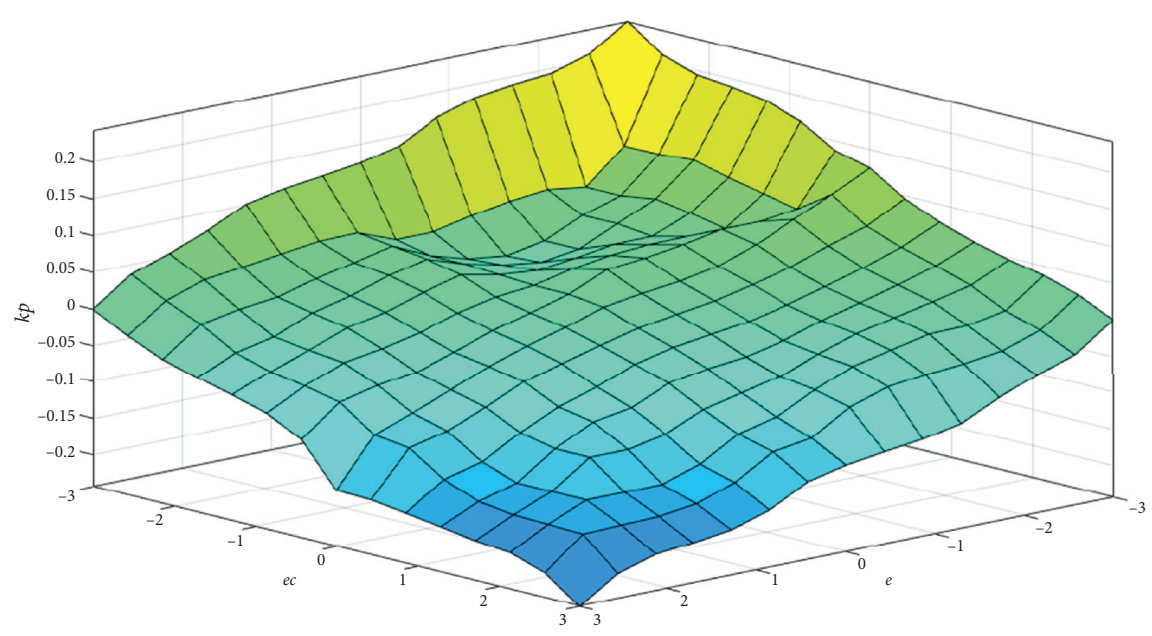

(a)

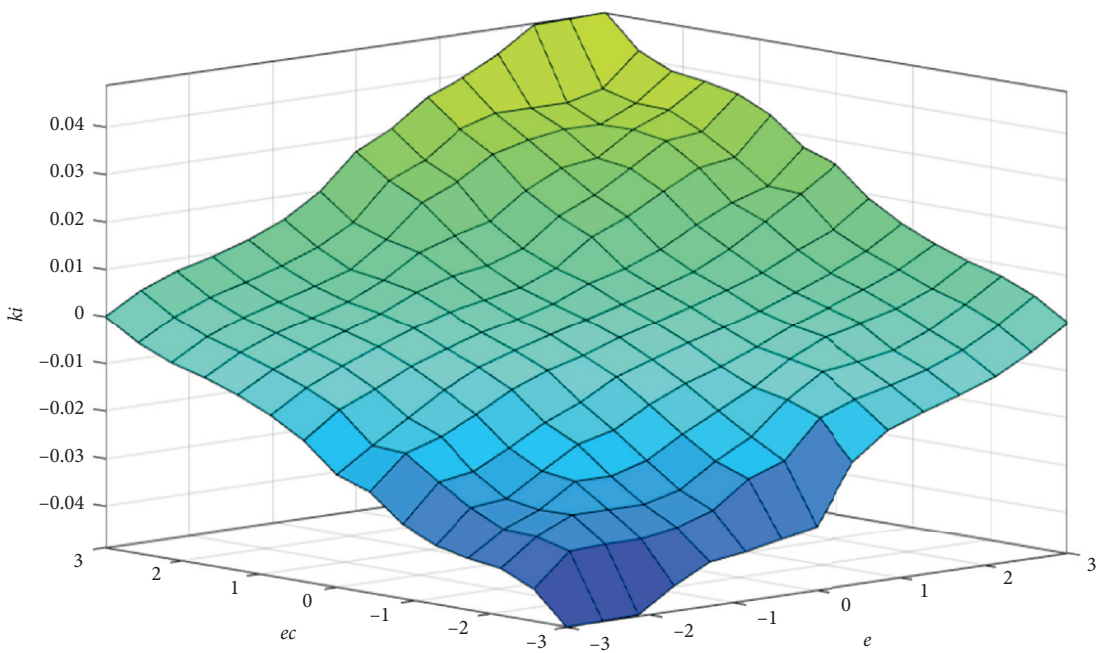

(b)

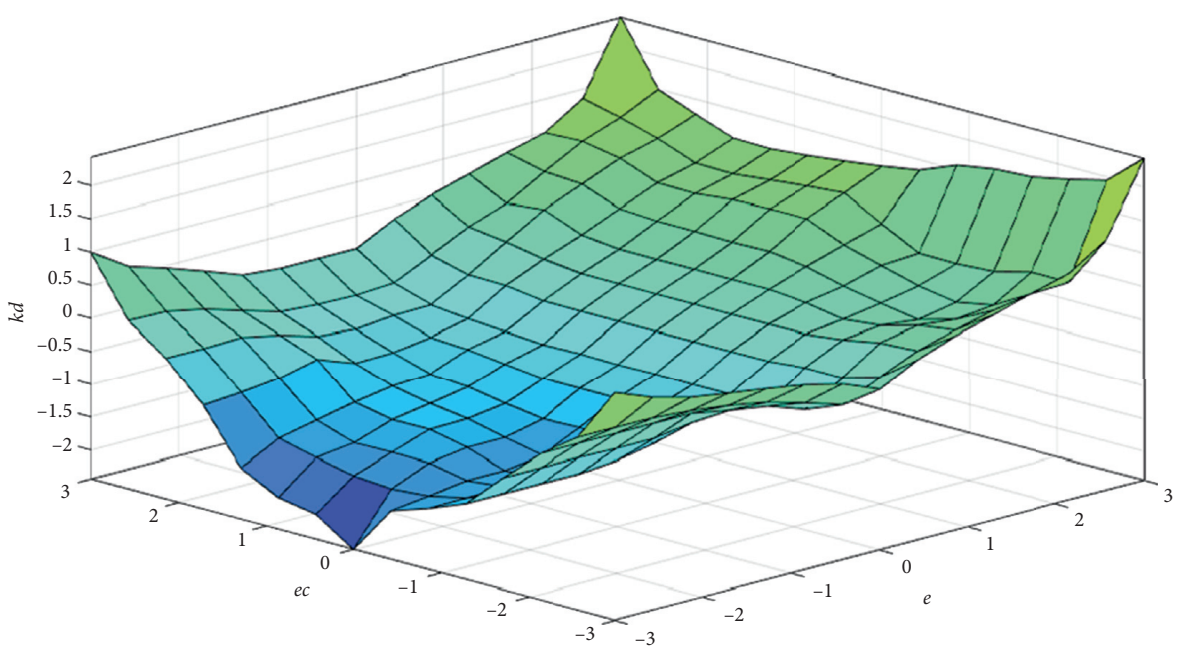

(c)

FIgURe 11: Surface map of F-PID controller. (a) $k p$. (b) $k i$. (c) $k d$. 


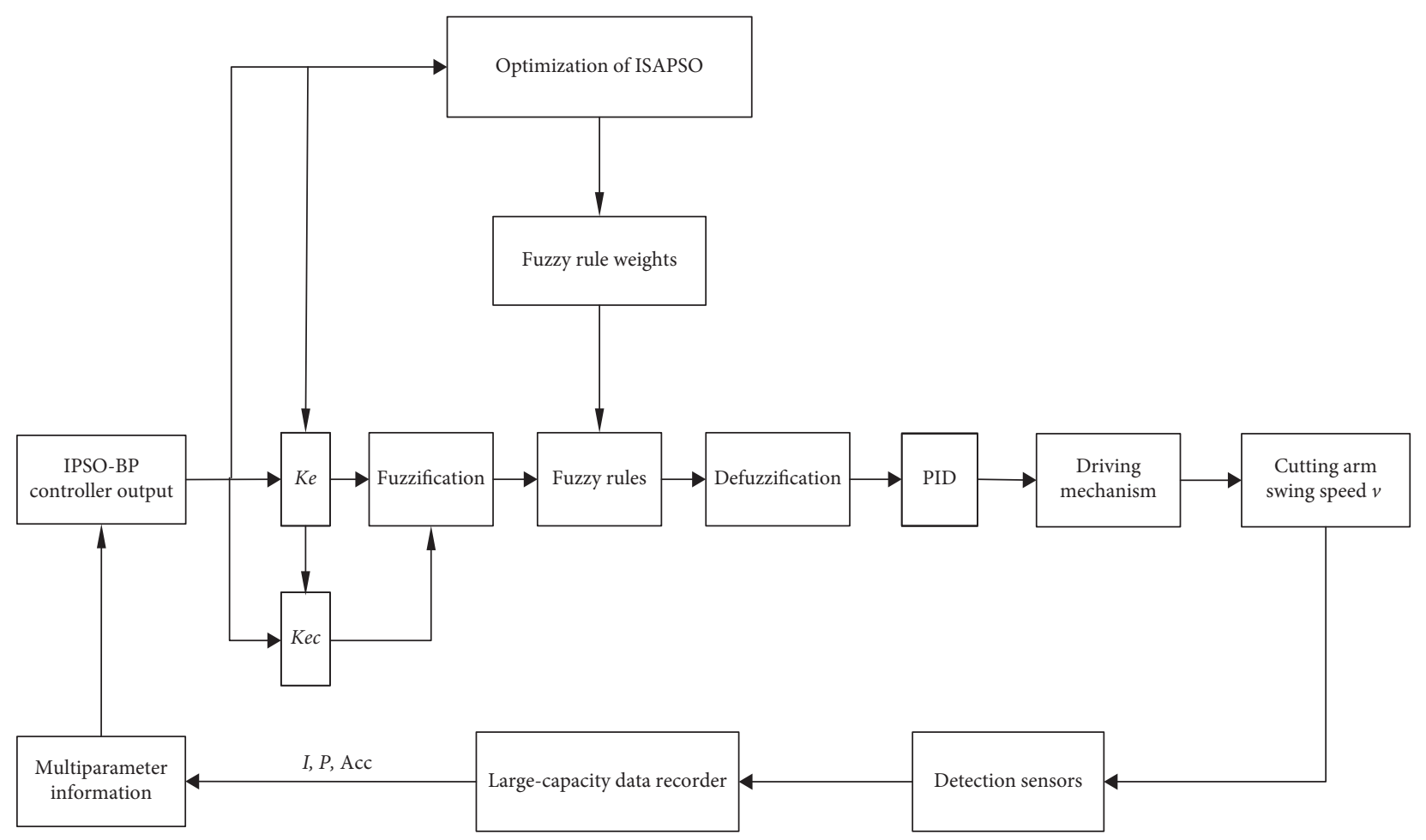

FIGURE 12: F-PID controller optimization schematic diagram.

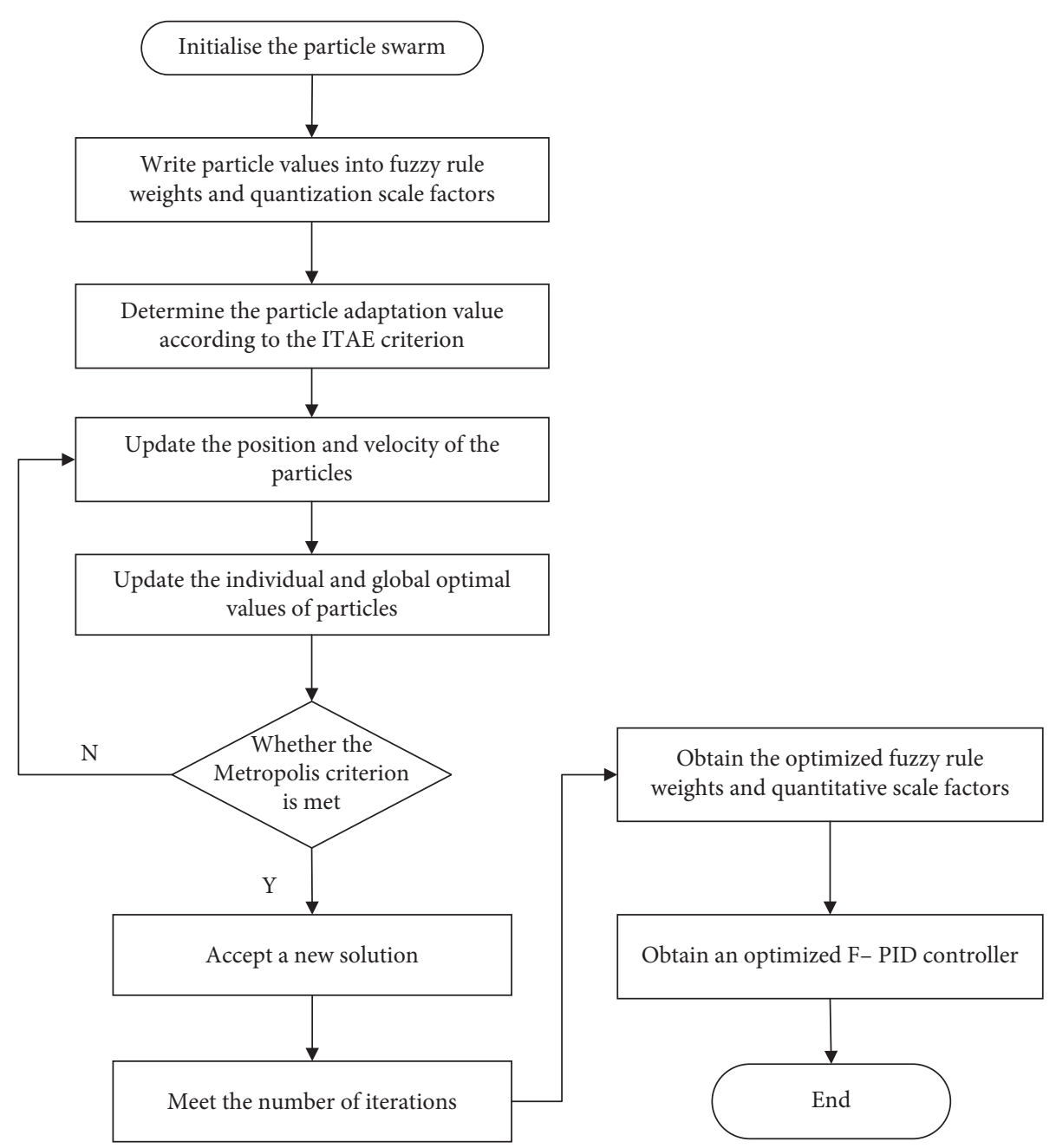

FIGURE 13: ISAPSO optimization algorithm flow chart. 


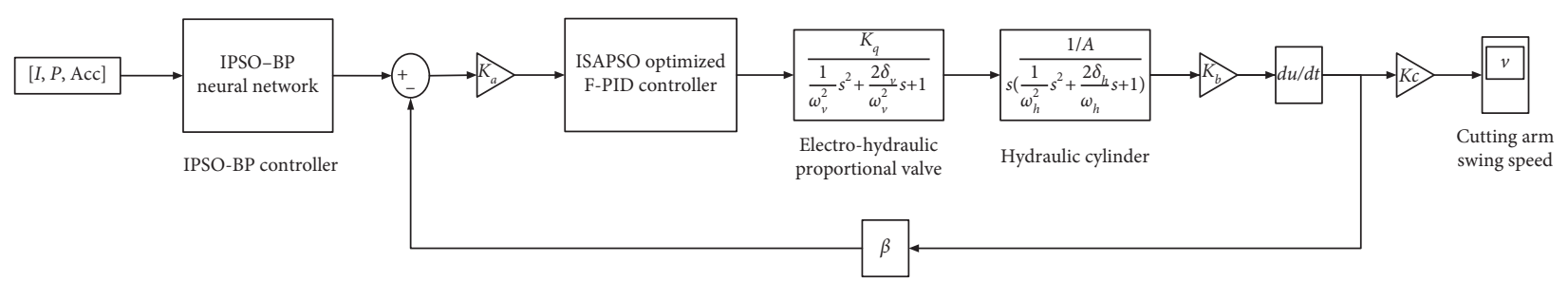

FIGURE 14: Block diagram of the cutting control system for cutting arm swing speed.

arm, and $B(s)$ is the swing angle displacement of the cutting arm.

The mathematical model of the conversion link between the cylinder stroke and the swing angle of the cutting arm is

$$
v=K_{c} \frac{\mathrm{d} B(s)}{\mathrm{d} t}
$$

In equation (13), $K_{c}$ is the conversion gain between the swing speed and the swing angle speed, and $v$ refers to the cutting arm swing speed.

In the control system, $\beta$ is the load signal conversion gain. The control system is as shown in Figure 14.

5.2. Simulation Results of the Control System. Three control systems are established in Simulink to compare the optimized multiparameter control method (OMC), the unoptimized F-PID control method, and the conventional PID control method. The parameters of the control system are set using the EBZ160 roadheader as an example. Through referring to relevant literatures of the same or similar roadheader type and relevant calculations, the parameters of every link of the control system have been obtained, as shown in Table 5 [13, 55-57].

The different sizes of multiparameter information $[I, P$, Acc] are inputted into the control system. Figures 15 and 16 show the simulation results for the three controllers.

According to Figures 15 and 16, the control system can adaptively change the swing speed of the cutting arm based on different multiparameter information and reach the desired swing speed. The OMC control method has a shorter response time than the F-PID and conventional PID methods and is essentially free of overshoot. According to Figures 16(a) and 17(a), the swing speed increases obviously and attains the desired value while inputting a small signal. As shown in Figures 16(b) and 17(b), the cutting arm swing speed increases the speed appropriately and ensures the cutting efficiency while inputting a middle signal. As shown in Figures 16(c) and 17(c), the cutting arm swing speed is rapidly reduced to protect cutting picks and cutting structural components while inputting a high signal.

The parameters response is shown in Table 6. OMC method is $22 \%$ faster than F-PID method and $69 \%$ faster than conventional PID from the response time. In terms of overshoot, compared with F-PID method and conventional PID, OMC controller has no overshoot. As a result, the OMC method offers better control accuracy and shorter response times.
TABle 5: Parameters of the control system.

\begin{tabular}{lc}
\hline Parameter & Value \\
\hline$K_{a}$ & 0.2 \\
$A$ & $0.025 \mathrm{~m}^{2}$ \\
$\delta_{h}$ & 0.18 \\
$\omega_{h}$ & $55.57 \mathrm{rad} / \mathrm{s}$ \\
$K q$ & $3.5 \times 10^{-4} \mathrm{~m}^{3} /(\mathrm{s} \cdot \mathrm{A})$ \\
$\omega_{v}$ & $157.1 \mathrm{rad} / \mathrm{s}$ \\
$\delta_{v}$ & 0.6 \\
$K_{b}$ & 80 (horizontal cutting process) \\
& 137.78 (vertical cutting process) \\
$K_{c}$ & 3.5 (horizontal cutting process) \\
$\beta$ & 2.8 (vertical cutting process) \\
\hline
\end{tabular}

\section{Experimental Studies}

The validation experiments were carried out in Shijiazhuang Coal Mine Machinery Co., Ltd. A large amount of multiparameter information has already been collected. Therefore, we only need to use the acquired multiparameter information to verify the control method. The variation of the cutting arm swing speed during the experiment is obtained by the numerical change rate of the cylinder stroke sensor. The experimental process is presented in Figure 17.

As shown in Figure 17, the upper computer is a personal computer, and the lower computer is a PCC industrial control computer. The experiment employs the control handle in the top left corner to simulate the cutting process of the roadheader and show the changes in relevant parameters in the top right corner. The control parameters $[I, P$, Acc $]$ are inputted via the upper computer. The variation of the cutting arm swing speed for different cutting states is as shown in Figure 18.

According to the experimental results shown in Figures 18(a) and 18(b), this method can adaptively adjust the swing speed of the cutting arm according to multiparameter information of different cutting states. When the roadheader is kept in a coal cutting state, the swing speed of the cutting arm is cut at a certain speed. When the roadheader encounters coal and rock inclusions and hard rock, the swing speed decreases rapidly to protect the cutting picks and cutting structural components. When the roadheader cuts a soft coal, the swing speed increases rapidly, and the cutting efficiency is improved. In the experiment, the response time of this method is basically around $0.8 \mathrm{~s}$ with no overshoot. Therefore, it is experimentally demonstrated that the method can control cutting arm swing speed with high control accuracy and robustness. 


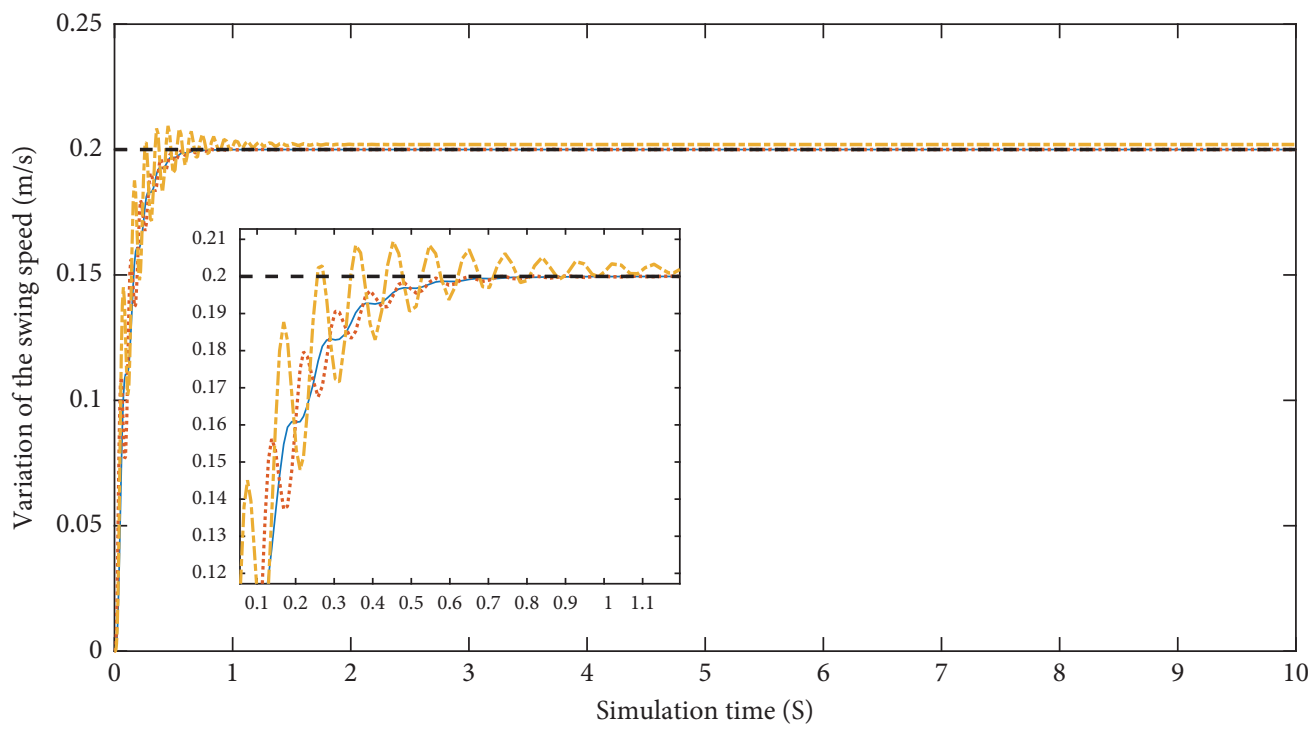

- OMC

F-PID

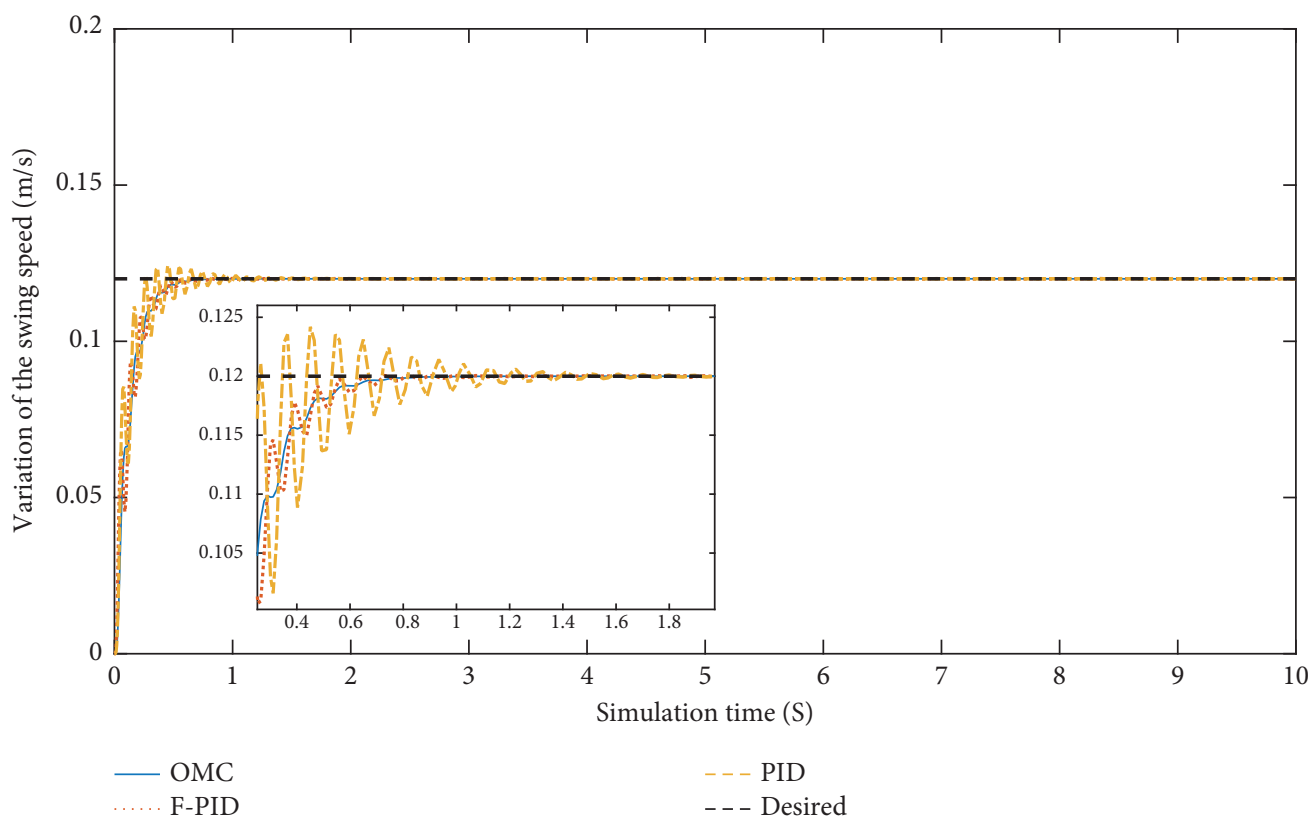

(b)

FIgURE 15: Continued. 


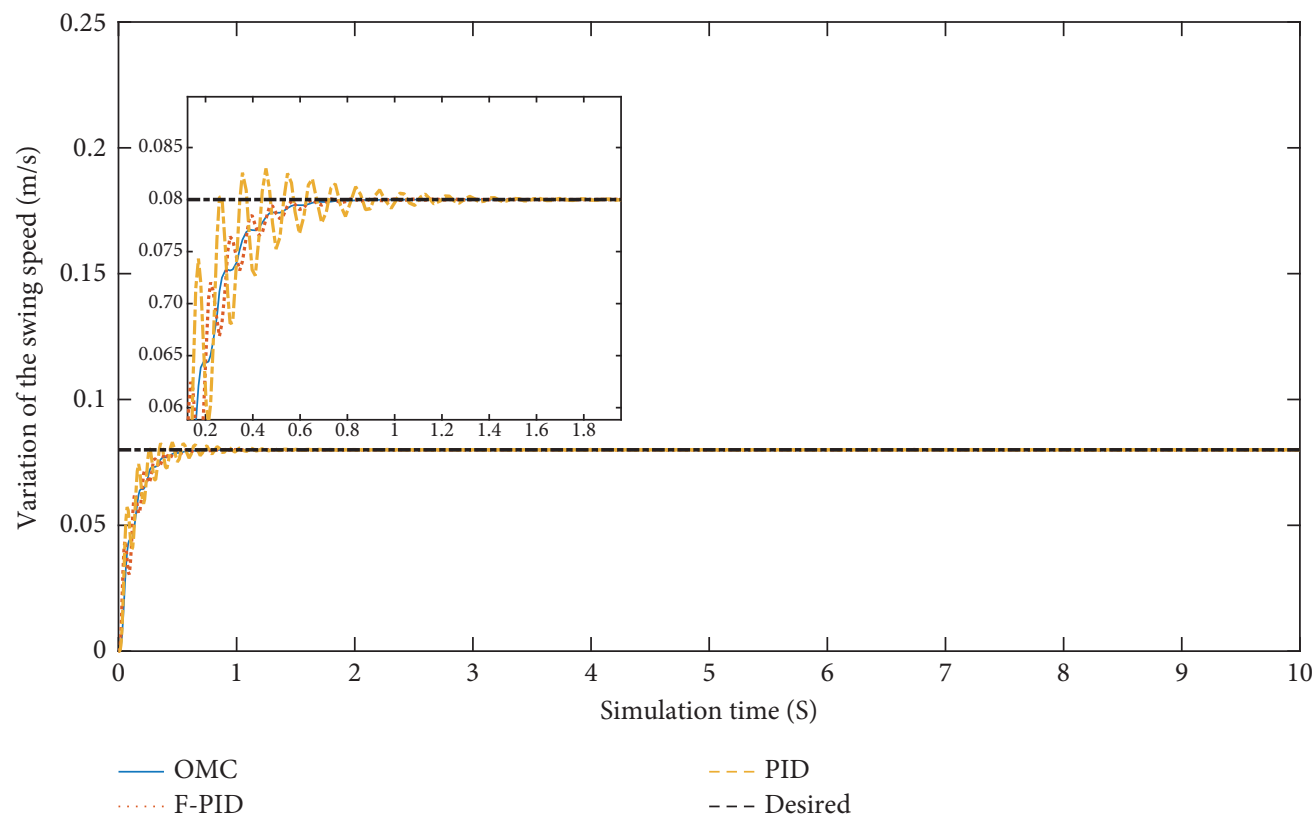

(c)

FIGURE 15: Control effect in horizontal cutting condition. Cutting arm swing speed at (a) small signal inputs, (b) middle signal inputs, and (c) high signal inputs.

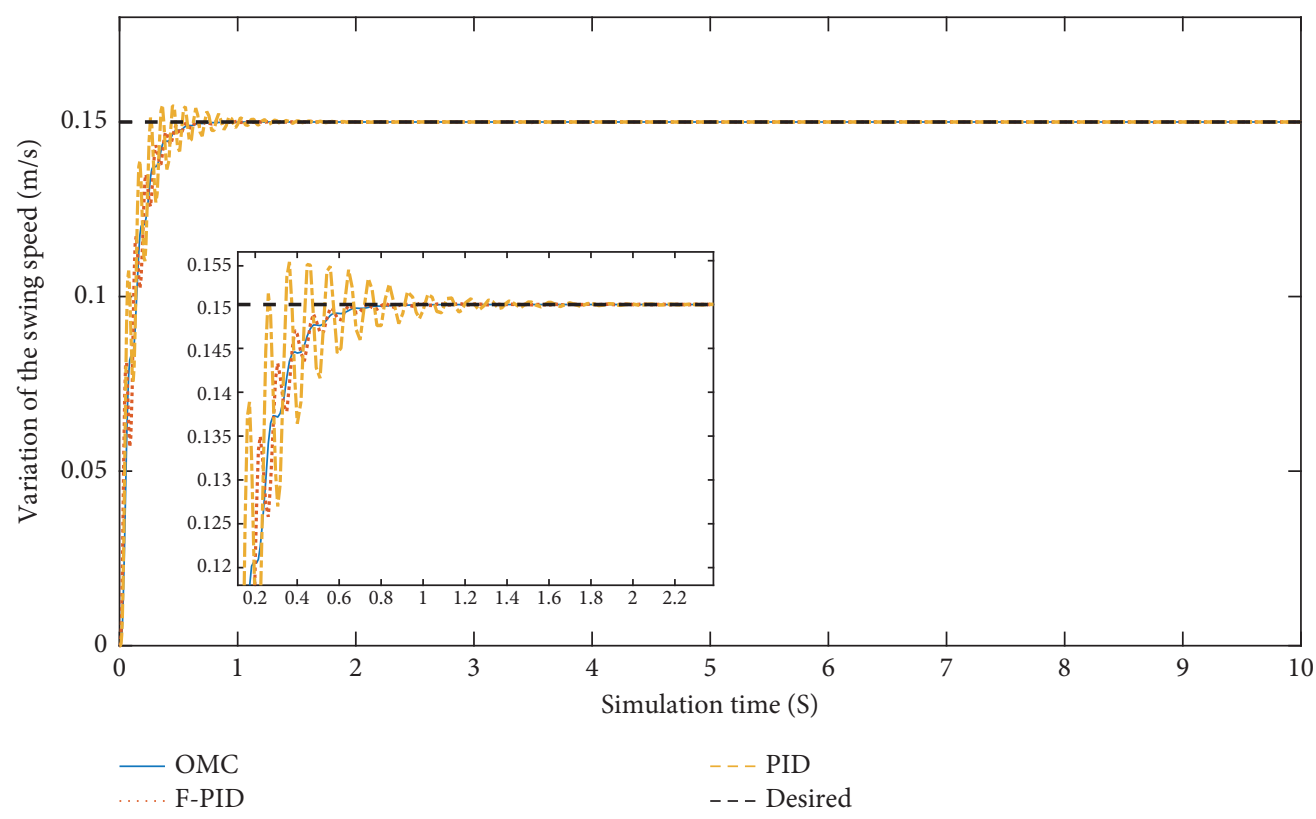

(a)

FIgURE 16: Continued. 


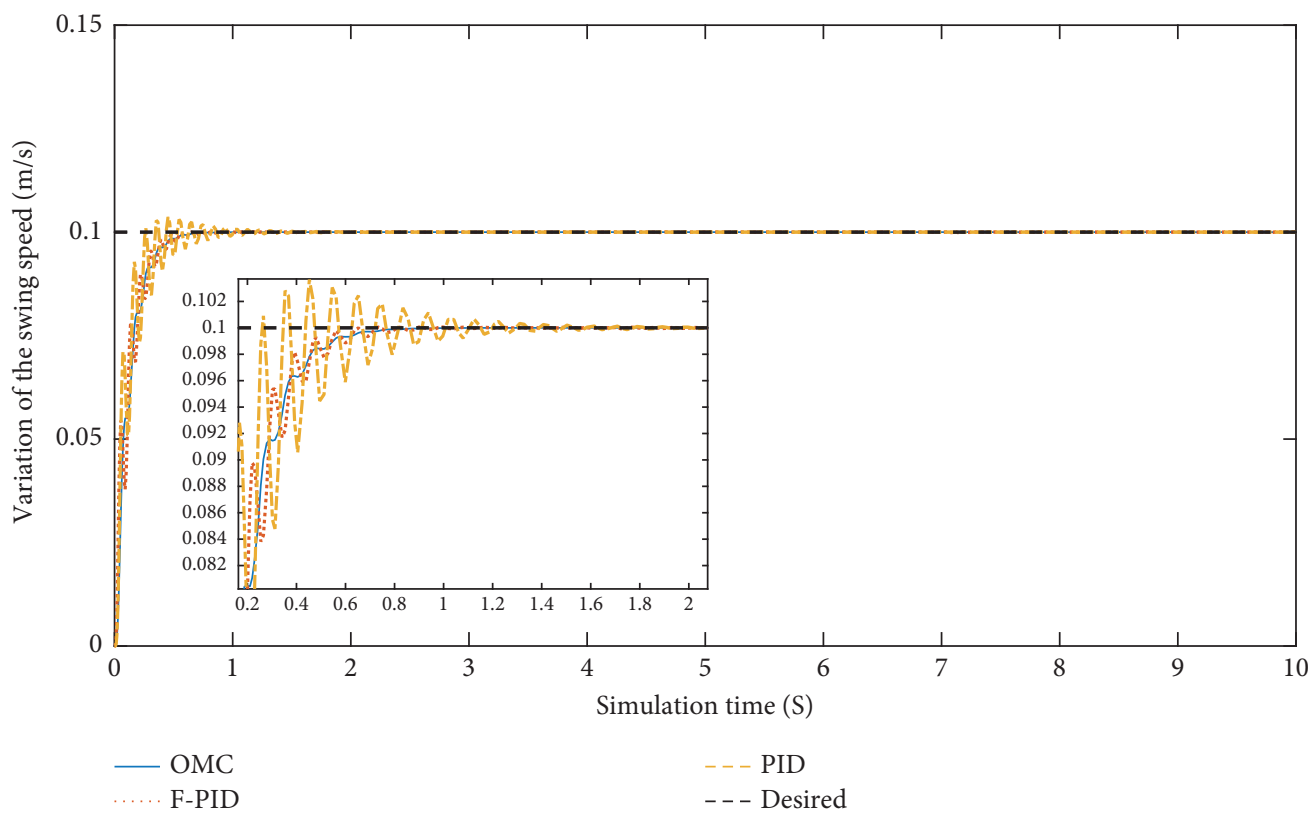

(b)

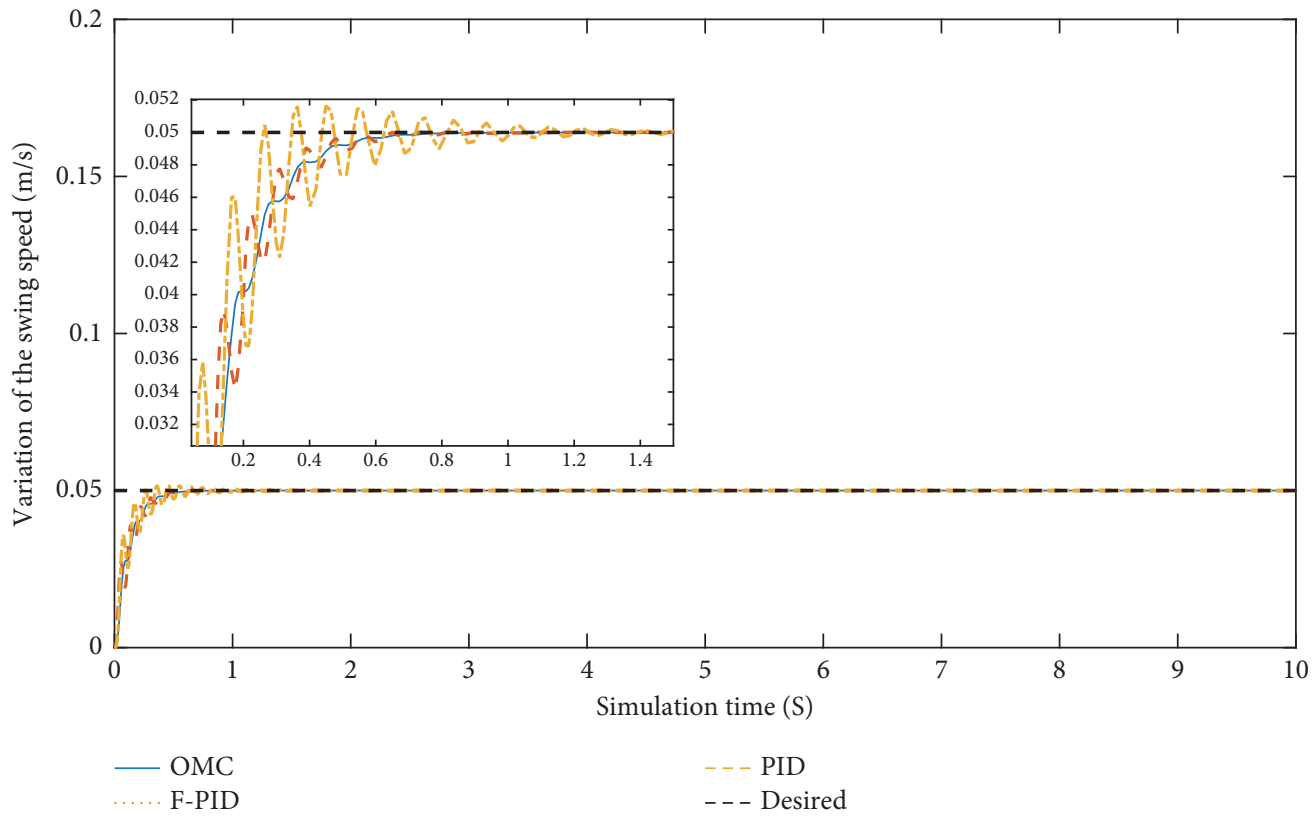

(c)

FIgURE 16: Control effect in vertical cutting condition. Cutting arm swing speed at (a) small signal inputs, (b) middle signal inputs, and (c) high signal inputs.

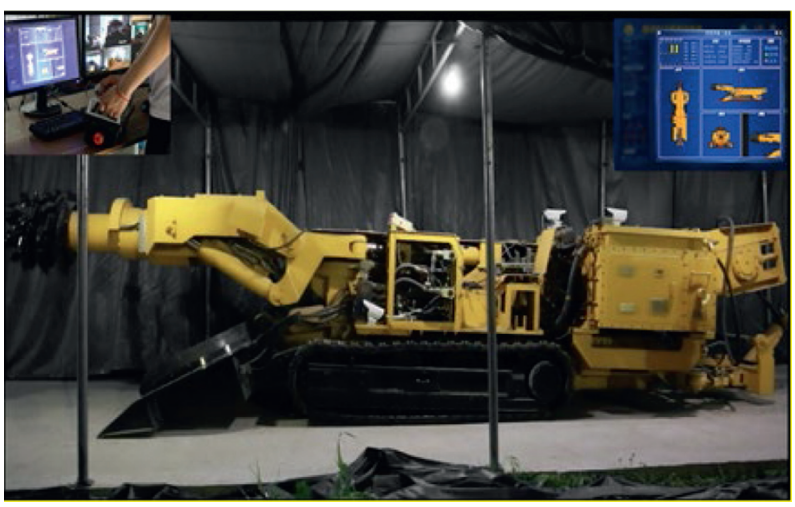

Figure 17: Experimental site plan. 
TABle 6: Parameters of the control system response.

\begin{tabular}{lccr}
\hline Control method & OMC & F-PID & \\
\hline Response time (average) (s) & 0.7 & 0.9 & PID \\
Overshoot (average) (\%) & 0 & 0.8 & 1.45 \\
\hline
\end{tabular}

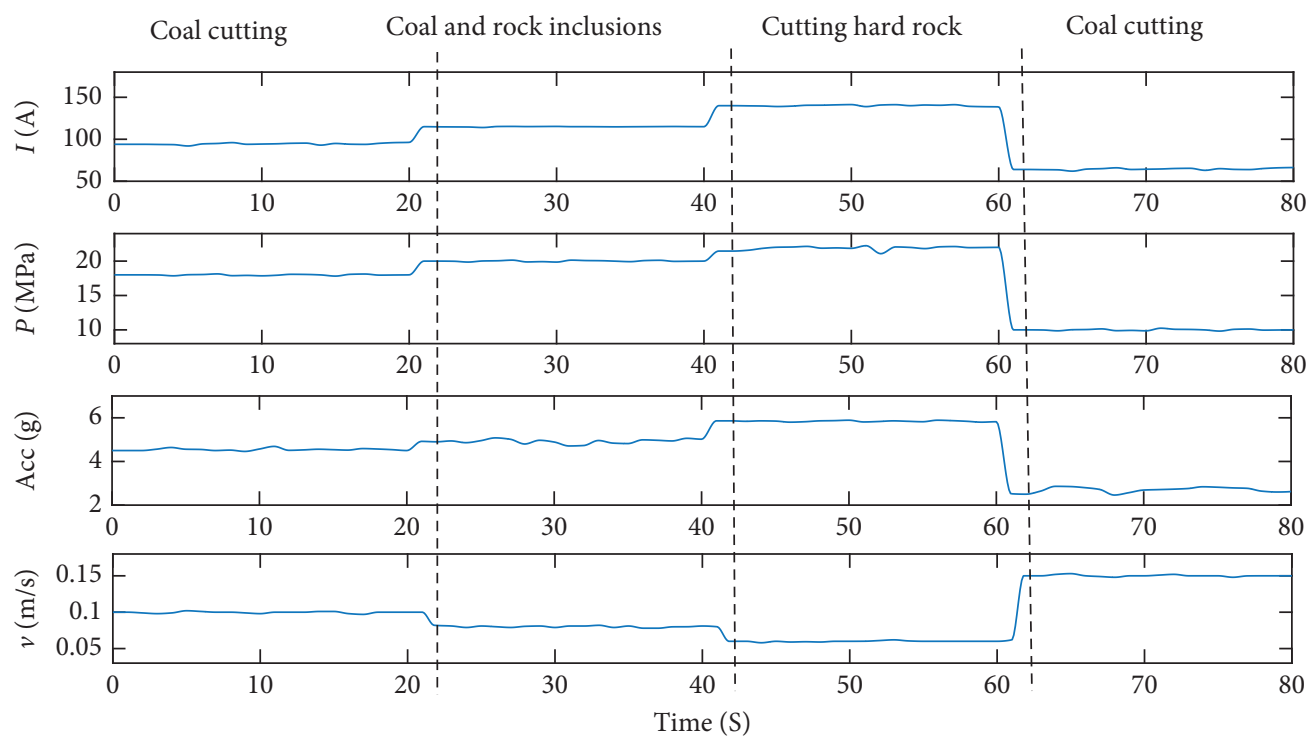

(a)
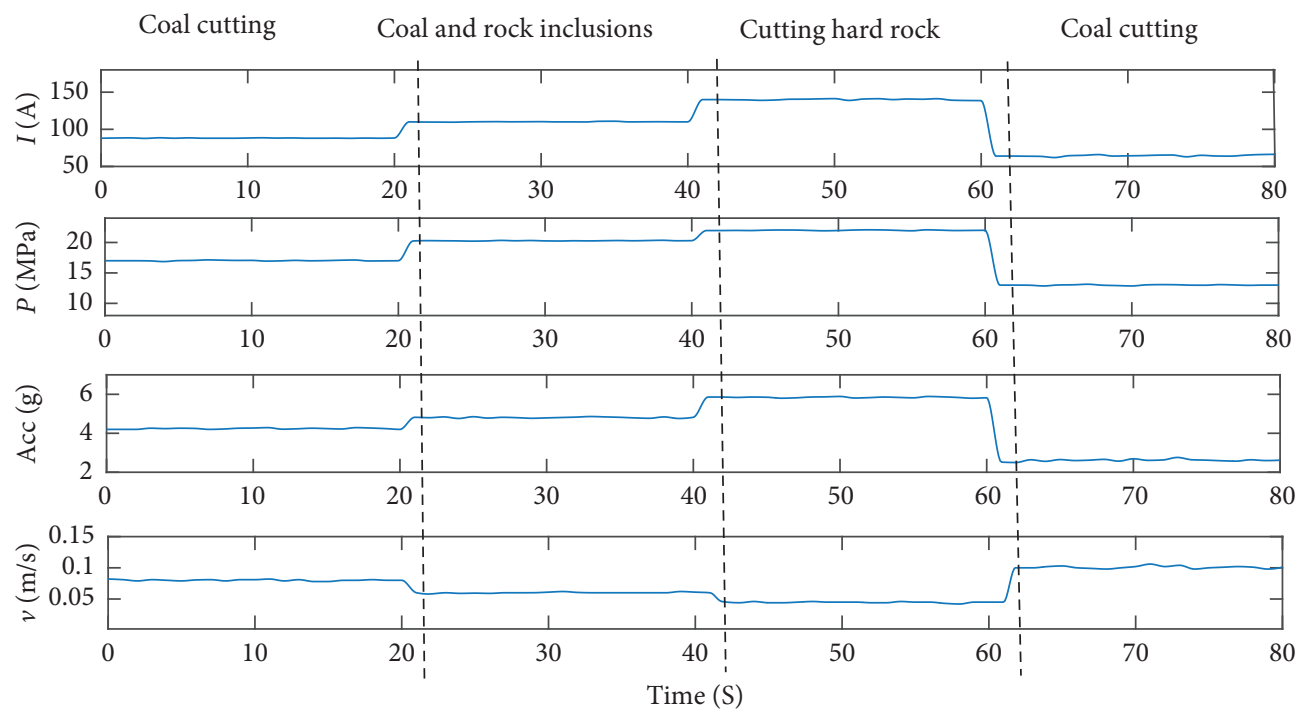

(b)

FIGURE 18: Variation of the cutting arm swing speed under different cutting conditions. Variation of swing speed under (a) horizontal cutting condition and (b) vertical cutting condition.

\section{Conclusions}

This study proposes a multiparameter control strategy and method for cutting arm swing speed of roadheader. A control strategy for cutting arm swing speed has been proposed. The improved particle swarm-optimized BP neural network algorithm (IPSO-BP) has been used to design the controller to identify the cutting load. A fuzzy
PID controller optimized with improved simulated annealing particle swarm optimization (ISAPSO) is used to realize the swing speed control of the cutting arm. Simulation analysis proves that this method can lead to higher control accuracy and faster response.

Experiments have verified the effectiveness of the control method. The method provides a theoretical and practical basis for realizing intelligent and unmanned cutting of 
roadheader. Moreover, it can be further applied and improved in underground coal mines. The synergistic control of the cutter arm swing speed and the cutter head speed of the roadheader will be the subsequent research interest.

\section{Data Availability}

The data used to support the findings of this study are available from the corresponding author upon request.

\section{Conflicts of Interest}

The authors declare that they have no conflicts of interest.

\section{Acknowledgments}

This work was supported by the National Natural Science Foundation of China (51874308).

\section{References}

[1] S. Deshmukh, A. K. Raina, V. M. S. R. Murthy, R. Trivedi, and R. Vajrea, "Roadheader-a comprehensive review," Tunnelling and Underground Space Technology, vol. 95, 2020.

[2] G. Wang and D. Zhang, "Innovation practice and development prospect of intelligent fully mechanized technology for coal mining," Journal of China University of Mining \& Technology, vol. 47, no. 3, pp. 459-467, 2018.

[3] S. Ge, H. Shangqing, and S. Zhang, "The status-of-art and key autonomous technology of smart coal mining in China," Coal Science and Technology, vol. 7, pp. 1-18, 2020.

[4] J. Yang, Q. Zhang, and C. Wang, "Research status and development of robotization of coal mine roadheader," Journal of China Coal, vol. 3, pp. 1-12, 2020.

[5] K. Zong, P. Zhang, and P. Wang, "Multifactor Analysis of roadheader's body pose responses during the horizontal cutting process," Shock and Vibration, vol. 2018, p. 18, Article ID 2387408, 2018.

[6] Y. Shen, S. Fu, P. Wang et al., "A scheme of MEMS-SINS initial alignment aided by laser spot perception system for the boom-type roadheader," Mathematical Problems in Engineering, vol. 2020, Article ID 3101203, 13 pages, 2020.

[7] S. Wang and M. Wu, "Cutting trajectory planning of sections with complex composition for roadheader," in Proceedings of the Institution of Mechanical Engineers-Part C: Journal of Mechanical Engineering Science, vol. 233, no. 4, pp. 1441-1452, May 2019.

[8] Y. Yang, G. Li, and A. Yuan, "Performance analysis of a hybrid power cutting system for roadheader," Mathematical Problems in Engineering, vol. 2017, Article ID 1359592, 12 pages, 2017.

[9] S. E. Seker, "Performance prediction of roadheaders using ensemble machine learning techniques," Neural ComoutingeApplications, vol. 31, no. 4, pp. 1103-1116, 2019.

[10] P. Cheluszka, R. Kaula, A. Heyduk, and J. Gawlik, "Modelling the dynamics of a drive of Boom-type Roadheader cutting heads at adjustable angular speed," Archives of Mining Sciences, vol. 63, no. 1, pp. 183-204, 2018.

[11] Y. Chen, A. Lu, and X. Mao, "Nonlinear dynamics mechanism of rock burst induced by the instability of the layer-crack plate structure in the coal wall in deep coal mining," Shock and Vibration, vol. 2017, Article ID 4051967, 12 pages, 2017.
[12] R. S. Faradonbeh, A. Salimi, and M. Monjezi, "Roadheader performance prediction using genetic programming (GP) and gene expression programming (GEP) techniques," Environmental Earth Sciences, vol. 76, no. 16, p. 584, 2017.

[13] H. Ergin and O. Acaroglu, "The effect of machine design parameters on the stability of a Roadheader," Tunnelling and Underground Space Technology, vol. 22, no. 1, pp. 80-89, 2007.

[14] H. Jian-sheng, "Present status and outlook of key technologies for mine roadway heading equipment," Coal Science and Technology, vol. 42, no. 8, pp. 69-74, 2014.

[15] P. Cheluszka, P. Sobota, and G. Gluszek, "Studies of behaviour of the automatic control system of roadheader cutting heads movement," in Proceedings of the 3rd International Conference of Computational Methods in Engineering Science (CMES 18), vol. 252, pp. 1-6, Kazimierz Dolny, Poland, January 2019.

[16] L. S. Zhang, Y. Y. Zhao, and J. Tian, "Load spectrum of roadheader cutting head in actual working conditions," Coal Engineering, vol. 48, no. 1, pp. 133-135, 2016.

[17] P. Wang, Y. Shen, K. Zong et al., "Multi-parameter information-based adaptive control method for cutting head speed of roadheader," in Proceedings of the Institution of Mechanical Engineers, Part C: Journal of Mechanical Engineering and Sciences, vol. 235, no. 11, pp. 1941-1955, August 2020.

[18] W. Yang and Z. Wang, "Research on the adaptive control for cutting operation of roadheader," Applied Mechanics and Materials, vol. 270, pp. 1436-1439, 2013.

[19] X. Li and Z. Liu, "Constant power control of cutting machine cutting motor based on GAs fuzzy control," Journal of Computer Systems, vol. 21, no. 5, pp. 149-152, 2012.

[20] W. He and K. Jiao, "Design of constant power control system for roadheader based on fuzzy PID," Coal engineering, vol. 51, no. 9, pp. 178-181, 2019.

[21] F. Gao, S. Y. Wang, and J. Gao, "Research of automatic control method of swing speed of cutting arm of roadheader," Industry \& Mine Automation, vol. 37, no. 8, pp. 38-41, 2011.

[22] X. Y. Huang, B. L. Yan, and W. L. Yang, "Research on adaptive cutting operation of roadheader," Coal Mine Machinery, vol. 34, no. 10, pp. 42-44, 2013.

[23] Z. Huang, "Nonlinear dynamic analysis of cutting head-rotorbearing system of the roadheader," Journal of Mechanical and Technology, vol. 33, no. 3, pp. 1033-1043, 2019.

[24] A. Ebrahimabadi, M. Azimipour, and B. Ali, "Prediction of roadheaders' performance using artificial neural network approaches (MLP and KOSFM)," Journal of Rock Mechanics and Geotechnical Engineering, vol. 7, no. 5, pp. 573-583, 2015.

[25] D. Jasiulek and K. Stankiewicz, "An adaptive control system of roadheader with intelligent modelling of mechanical features of mined rock," Journal of KONES Powertrain and Transport, vol. 18, no. 2, pp. 197-203, 2011.

[26] D. Jasiulek and J. Świder, "Mechatronic systems in mining roadheaders - examples of solutions," Pomiary Automatyka Robotyka, vol. 1, pp. 121-127, 2013.

[27] L. Zhao and J. Wang, "Cutting performance evaluation of a roadheader machine by PCA and RBF," Simulation-Transcation of the Society for Modeling and Simulation International, vol. 94, no. 12, pp. 1129-1141, 2018.

[28] J.-J. Yang, S.-c. Fu, H. Jiang, X.-y. Zhao, and M. Wu, "Recognition of cutting hardness of coal rock properties based on fuzzy criteria," Journal of China Coal Society, no. S2, pp. 540-545, 2015.

[29] W. Wang, Y. Lin, and T. Wang, "Dynamic load identification method of rock roadheader using multi neural network and evidence theory," in Proceedings of the IEEE International 
Conference on Mechatronics and Automation, vol. 252, pp. 1238-1243, Harbin, China, August 2016.

[30] A. Modiri and S. Mobayen, "Adaptive terminal sliding mode control scheme for synchronization of fractional-order uncertain chaotic systems," ISA Transactions, vol. 105, pp. 33-50, 2020.

[31] S. M. Esmaeilzadeh, M. Golestani, and S. Mobayen, "Chattering-free fault-tolerant attitude control with fast fixed-time convergence for flexible spacecraft," International Journal of Control, Automation, and Systems, vol. 19, no. 1, 2020.

[32] G. Pujol-Vazquez, S. Mobayen, and L. Acho, "Robust control design to the furuta system under time delay measurement feedback and exogenous-based perturbation," Mathematics, vol. 8, no. 12, 2020.

[33] R. Rahmani, S. Mobayen, and J.-S. Ro, "Robust passivity cascade technique-based control using RBFN approximators for the stabilization of a cart inverted pendulum," vol. 9, no. 11, 2020.

[34] M. Elsisi, M. Soliman, M. Aboelela et al., "GSA-based design of dual proportional integral load frequency controllers for nonlinear hydrothermal power system," World Academy of Science, Engineering and Technology, vol. 9, 2015.

[35] E. S. Ali and S. M. Abd-Elazim, "Bacteria foraging optimization algorithm based load frequency controller for interconnected power system," International Journal of Electrical Power \& Energy Systems, vol. 33, no. 3, pp. 633-638, 2011.

[36] A. Du, Y. Chen, D. Zhang et al., "Multi-objective energy management strategy based on PSO optimization for powersplit hybrid electric vehicles," Energies, vol. 14, 2021.

[37] A. K. Kashyap and D. R. Parhi, "Particle swarm optimization aided PID gait controller design for a humanoid robot," ISA Transactions, vol. 114, pp. 306-330, 2020.

[38] M. Elsisi, M. Q. Tran, K. Mahmoud et al., "Robust design of ANFIS based blade pitch controller for Wind energy conversion systems against Wind speed Fluctuations," IEEE Access, vol. 9, no. 99, p. 1, 2021.

[39] Y. Zhang, L. Cao, Y. Yue et al., "A novel coverage optimization strategy based on grey Wolf algorithm optimized by simulated annealing for wireless sensor networks," Computational Intelligence and Neuroscience, vol. 2021, no. 1, 14 pages, Article ID 6688408, 2021.

[40] L. Luo, Z. Zhang, and Y. Yin, "Simulated annealing and genetic algorithm based method for a bi-level seru loading problem with worker assignment in seru production systems," Journal of Industrial and Management Optimization, vol. 13, no. 5, 2017.

[41] Y. Yang, Q. Yuan-yuan, W. Liu et al., "Vibration analysis of working tunnel boring machine(TBM) in underground mine," Coal Technology, vol. 35, no. 7, pp. 240-242, 2016.

[42] L. Xu, S.-y. Wang, J. Xiao-dong, Y. Yang, C. Jing-bo, and M. Wu, "Load analysis of driving cylinder for EBZ160 roadheader baded on measured data," Coal Technology, vol. 35, no. 5, pp. 250-252, 2016.

[43] L. Zhang, Research on Load Spectrum Measurement and Analysis Method of Roadheader Based on Data Logger, China University of Mining and Technology, Beijing, China, 2017.

[44] Y. Yang, Research on Dynamic Characteristics of Key Structure of Roadheader Based on Vibration Test, China University of Mining and Technology, Beijing, China, 2017.

[45] Li Xu, Study on Mechanical Characteristics of Key Structures of Cantilever Roadheader, China University of Mining and Technology, Beijing, China, 2017.
[46] I. A. Basheer and M. Hajmeer, "Artificial neural networks: fundamentals, computing, design, and application," Journal of Microbiological Methods, vol. 43, no. 1, pp. 3-31, 2016.

[47] H. Zhou, Y. Zhou, and L. Zhu, "Implementation and comparison of improved BP neural network based on MATLAB," Computing Technology and Automation, vol. 27, no. 1, pp. 28-31, 2008.

[48] J. Yao, G. Jiang, and S. Gao, "Particle swarm optimizationbased neural network control for an electro-hydraulic servo system," Journal of Vibration and control, vol. 9, no. 20, pp. 1369-1377, 2014.

[49] H. Tao, Research on Railway Transportation Volume Forecast Based on Hybrid Intelligent Algorithm, Lanzhou Jiaotong University, Lanzhou, China, 2012.

[50] J. S. Wang and G. H. Yang, "Data-driven approach to accommodating multiple simultaneous sensor faults in variablegain PID systems," IEEE Transactions on Industrial Electronics, vol. 66, 2018.

[51] M. Tajjudin, M. H. F. Rahiman, N. Ishak, R. Adnan, and H. Ismail, "Comparison between optimally-tuned PID with self-tuning PID for steam temperature regulation," in Proceedings of the 2012 4th International Conference on Intelligent and Advanced Systems (ICIAS2012), vol. 2, pp. 551-556, Kuala Lumpur, Malaysia, June 2012.

[52] Y. Pan, X. Li, and H. Yu, "Efficient PID tracking control of robotic manipulators driven by compliant actuators," IEEE Transactions on Control Systems Technology, vol. 27, pp. 915-922, 2019.

[53] S. M. H. Mousakazemi and N. Ayoobian, "Robust tuned PID controller with PSO based on two-point kinetic model and adaptive disturbance rejection for a PWR-type reactor," Progress in Nuclear Energy, vol. 111, pp. 183-194, 2019.

[54] Q. Liu, Design and Application of Fuzzy Controller Based on Particle Swarm Optimization, Shenyang University of Technology, Shenyang, China, 2017.

[55] J. Zhang, Research on Control System with Automatic Forming and Constant Power Cutting of a Longitudinal axis Type Roadheader, Harbin Institute of Technology, Harbin, China, 2013.

[56] Z. Liu, Research on the Constant Power Speed Control System of Cutting Mechanism of Boom-type Roadheader, Liaoning Project Technology University, Jinzhou, China, 2012.

[57] N. Shao, Research of Dynamic Characteristics of the Hydraulic System of the Partial Cross Section Tunneling Machine, Liaoning Project Technology University, Jinzhou, China, 2007. 